\title{
Morfogénesis de la ensenada en zeta y de la terraza estuarial asociada en Pichilemu: prototipo para Chile Central ${ }^{1}$
}

\author{
José F. Araya Vergara \\ Departamento de Geografía, Universidad de Chile, jaraya@uchile.cl
}

Recibido, 22 de octubre de 2004; versión corregida y aceptada, 22 de julio de 2005.

\begin{abstract}
RESUMEN
Se propone un esquema evolutivo de la ensenada en zeta de Pichilemu. Los métodos usados se basaron en tres fundamentos derivados de la teoría acumulada: interacción entre oleaje oblicuo y costa desalineada, ajuste de los sedimentos al oleaje refractado y efecto de la transgresión flandesa. La aloestratigrafía local fue correlacionada con sistemas similares visitados en la región y con resultados sobre geocronología en algunos de ellos. El sistema analizado resulta de una interacción directa entre dos procesos principales: formación de ría con estuario y generación de una ensenada en forma de zeta. Esta última está muy asociada a una terraza estuarial, que puede correlacionarse con homólogas de Chile Central, lo que permite atribuirle una edad holocénica. Se encuentra que estos mecanismos fueron sincrónicos, cuyo desarrollo se puede sintetizar en cuatro momentos esenciales: efecto durante la transgresión, máximo del relleno transgresivo holocénico, efecto de balance entre ascenso del nivel del mar y elevación cortical recientes (formación de la terraza estuarial), y efecto de sobrecarga de sedimentos litorales.
\end{abstract}

Palabras clave: Línea de costa desalineada, ensenada en forma de zeta, ría progradada, sistema estuarial, terraza estuarial.

\section{Morphogenesis of the zeta form embayment and the associated estuarine terrace in Pichilemu: prototype for Central Chile ${ }^{1}$}

\begin{abstract}
An evolutive scheme is proposed for the embayment of Pichilemu. The used methods deal with three theoretical and fundamental principles: the interaction between oblique swell and offset coast, adjustment of sediments to refracted swell and effect of the frandrian transgression. The allostratigraphy of the system was correlated with similar cases visited in the region and with results on geochronology in some of them. The analyzed system results from an interaction between two principal processes: formation of ría including estuary and production of a zetaform embayment, associated to an estuarine terrace. This form is thought to be formed in the Holocene, starting from its correlation with homologous features of Central Chile. It is found that the two principal morphogenetical processes were sinchronic and that the development of which can be synthesized in four essential moments: effect during the transgression, maximum of the Holocenic transgression filling, effect of balance between recent sea level rise and cortical uplift (formation of the estuarine terrace), and modern effect of shore sediment overload.
\end{abstract}

Key words: Offset coastline, zetaform embayment, prograded ría, estuarine system, estuarine terrace.

1 Proyecto Análisis borde costero Pichilemu, Departamento de Investigación, Universidad de Chile 


\section{INTRODUCCIÓN}

Las características geométricas de las ensenadas existentes entre Puertecillo (al Norte de Pichilemu) y Cáhuil (Fig. 1) fueron establecidas por ARAYA-VERGARA (1983). Los resultados de este trabajo se pueden resumir como sigue:

Dos estilos morfoestructurales están presentes en esta línea de costa: a) Estilo desalineado (offset) con ensenadas en zeta y b) línea de costa crenulada y playas casi rectilíneas. Ellos resultan de líneas de costa contrapuestas, porque areniscas blandas sobreyacen a esquistos. Se observa así una irregularización costera por retroceso de los acantilados en areniscas y mayor resistencia de los esquistos a la erosión marina, permaneciendo como promontorios y arrecifes. Las ensenadas en zeta son resultado de los mayores desalineamientos. En ellas, la matriz de determinación indica que el ángulo de desalinamiento (offset), el índice de curvatura y la orientación con respecto al mar de fondo del SW concentran el mayor refuerzo de operación conjunta del sistema (ARAYAVERGARA 1983). La refracción del mar de fondo se muestra bien relacionada con los tres elementos, a partir de su buena correlación con la curvatura. Dependiendo de esta interacción, cada ensenada representa en su interior alineamiento por deriva y por vaivén.

Este análisis se encuentra bien sustentado por la teoría generada sobre contraposición de líneas de costa (CLAPP, en JOHNSON 1919), desalineamientos (offset, DAVIES 1977), bahías en forma de zeta (HALLIGAN 1906, en DAVIES 19977; KRUMBEIN, en DAVIES 1977; SYLVESTER 1960; YASSO 1965), curvatura y orientación (ARAYAVERGARA 1967 y 1982). A partir del desarrollo de la teoría que permite clasificar las zonas de rompiente de oleaje (WRIGHT \& SHORT 1984), fue posible categorizarlas en función de su distancia al origen (extremo sur o proximal) de una ensenada en zeta (ARAYA-VERGARA 1996). Se encontró una gradación sistemática del litoral cercano desde la zona proximal - con playas disipativas o reflectivas - a la distal, con playas intermedias, lo que también se halló en un seguimiento hecho por MARTÍNEZ (2001) en otras ensenadas. Conjuntamente, se encontró que la masa de la arena contenida en playas y dunas es mayor hacia la parte distal de estos sistemas (ARAYA-VERGARA 1996).

El funcionamiento presente de estas ensenadas en zeta debe haberse originado en relación con la operación de la transgresión flandesa. Esta asunción se fundamenta en varios trabajos en los lugares mostrados en la Fig. 1. En el seguimiento de biofacies transgresivas en la costa del Bio-Bio MARTÍNEZ (1968), se encontró antíguas líneas litorales en un espesor de unos $30 \mathrm{~m}$ de sedimentos bajo el nivel del mar actual: entre $\sim-26$ y $2 \mathrm{~m}$ se detectaron edades desde 9400 hasta 1500 años, representando importantemente ambientes estuariales. En la costa de Chile norte y central, registros de $\mathrm{C}^{14}$ obtenidos por OTA \& PASKOFF (1993), VILLA-MARTÍNEZ \& VILLAGRÁN (1997) y HERVÉ et al. (2003) indican una transgresión del Holoceno Medio, cuyos testimonios se halla a unos pocos metros sobre el nivel actual del mar. Un seguimiento altimétrico de ARAYA-VERGARA (1981) para niveles altos de la terraza que delimita varios estuarios en Chile Central, muestra valores frecuentes entre 4 y $7 \mathrm{~m}$. En especial, los valores más altos pueden reflejar influencias tectónicas co-sísmicas elevando la terraza (o a veces hundiéndola), según recopilación de HERVÉ et al. (2003), lo que explica sus diferencias de altura.

En el valle costero que enfrenta la ensenada de Pichilemu, la terraza estuarial parece corresponder a los niveles citados en el párrafo anterior, constituyendo un solo sistema con la ensenada. El propósito de este trabajo es proponer un esquema genético-evolutivo de esta última y relacionarla con sus homólogas de Chile Central. 


\section{MATERIALES Y MÉTODOS}

\section{Emplazamiento de la ensenada}

Entre Puertecillo y Cáhuil (Fig. 1) la configuración de la línea de costa está controlada preferentemente por fracturas oblícuas, algunas transversales - y en menor grado paralelas - a su dirección general (ARAYAVERGARA 1983). Como el desalineamiento que acompaña al sistema fractural permite individualizar las bahías en zeta, las mayo-

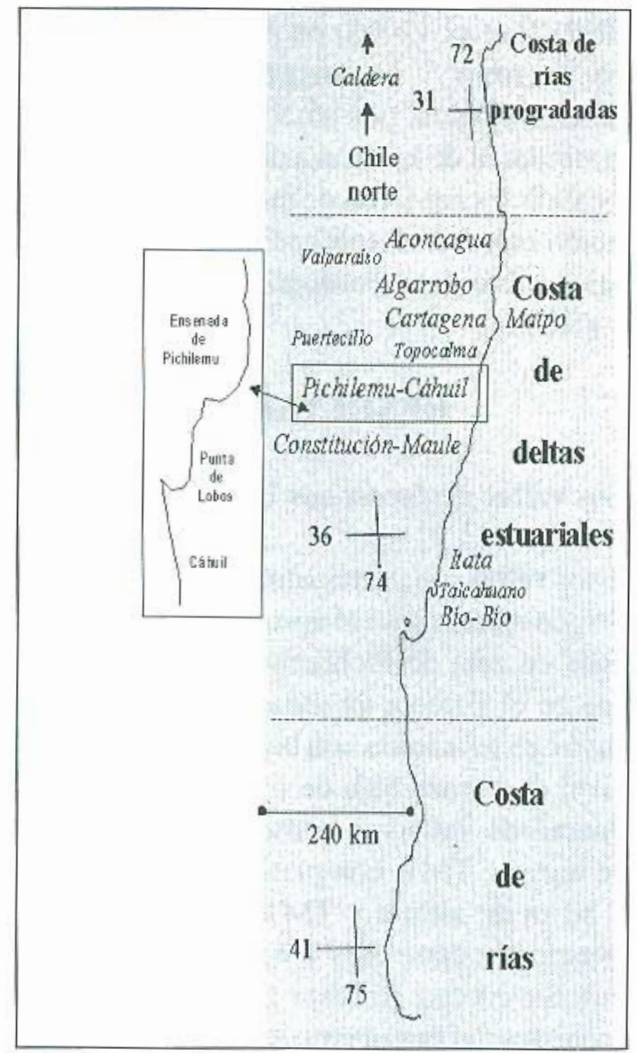

Fig. 1. Croquis de ubicación de la ensenada de Pichilemu en la costa de deltas estuariales en Chile Central. Los pequeños sistemas como éste pueden corresponder a rías progradadas, características de Chile semiárido.

Fig. 1. Locational sketch of the Pichilemu embayment in the coast of estuarine deltas of Central Chile. These small systems can be prograded rías, which are typical of semi-arid Chile. res de las cuales sustentan sistemas estuariales, se puede asumir que las estructuras favorecieron la formación de valles costeros. Por ello, las rías y estuarios de la región se encuentran en las entrantes mayores. El oleaje de mar de fondo que con más frecuencia ataca a estas ensenadas tiene dirección SW, impactando en forma oblicua a las zonas distal y media y como trenes refractados en la zona proximal.

\section{Procedimientos}

La elección de los hechos observados se basa en tres tipos fundamentales de experiencias. Primero, el experimento de SILVESTER (1969) indica que olas de mar de fondo (swell) que se aproximan a la línea de costa con promontorios en ángulo de $45^{\circ}$ con respecto a su dirección general, producen bahías en zeta en su interacción con los sedimentos. En Chile Central, el mar de fondo frecuente ataca en este tipo de ángulos. Segundo, la forma en zeta o medio corazón, deriva de un ajuste al mar de fondo refractado (CHAPMAN 1982), lo que debe reflejarse en la distribución de los tipos de zona de rompiente y en la interacción playa-duna. Y tercero, la operación de la Transgresión Flandesa debe traducirse en dos grandes tipos de facies: de playa, expresada en cordones litorales (barras, barreras o flechas); y lagunares, debido al efecto de represa de las primeras (MARTIN et al. 1993).

\section{Pre terreno}

Para observar los rasgos característicos de este tipo de fenómeno se trabajó con fotografías aéreas Hykon 1: 70.000 (1955), OEA 1: 30.000 (1962), SAF 1: 30.000 (1978), San Fernando FONDEF-SAF 1:20.000 (1994), GEOTEC-SAF 1: 70.000 (1997), VI Región Pichilemu-SAF 1: 8.000 (1998) y con las cartas topográficas 1: 25.000 (plancheta IGM) y 1: 50.000 (IGM). De las cartas indicadas, la plancheta al 25.000 resultó verdaderamente útil, por la indicación de cotas además de las curvas de nivel, el buen contraste representado entre fondos planos y flancos de valle y 
la figuración de cotas en el litoral arenoso. En cambio, estas indicaciones son pobres en la carta al 50.000, no sólo por lo inherente a su escala, sino también por la diferencia de criterio con que está hecha (la información extra de terreno es menor). Desde fotografías y cartas resultaron 12 categorías de formas, las que fueron cotejadas en terreno.

\section{Terreno}

En esta etapa, se priorizó la identificación de la terraza baja ( en adelante Te), teniendo como guía importante la carta al 25.000 debido a la prolija anotación de cotas en su superficie cerca de la laguna estuarial. Las escarpas de borde de terraza que presentan buena exposición de sedimentos se ubican a $\sim 1,5 \mathrm{~km}$ del mar. Corresponden a orillas de meandros incididos. Los rasgos observados en cada corte están sintetizados en la Tabla 1. Se visitó también las partes más deprimidas de la terraza en las inmediaciones de la laguna estuarial, debido a sus conexiones con las variaciones de tamaño de ésta y con el origen de la plataforma de terraza. Se observó la relación de altura entre el sector de la laguna y el cordon litoral que sirve de barrera. La altitud de la terraza fue establecida por nivelación del perfil de la playa, a partir del nivel de máxima resaca de la ola en marea media. Se usó el método de mira y horizonte de Emery, estableciendo la altitud del nivel de la laguna (mayor que el nivel del mar), a la cual se sumó la altura de las escarpas observadas. Para poder caracterizar la barrera litoral, la playa fue recorrida en su totalidad, procediendo al levantamiento de perfiles también con el método de Emery. Se clasific 6 la zona de rompientes, según el sistema de WRIGHT \& SHORT (1984), comparando estas categorías con las observadas en las fotografías aéreas, para determinar las características de las barras asociadas a la playa. Los perfiles y sus partes fueron clasificados usando la sistemática de ARAYAVERGARA (1986). Los sistemas de dunas internas fueron visitados en los años 80's antes de la forestación que las cubre actualmente, atendiendo a su diferencia de evolución según el estado de su forma. Las antedunas (foredunes) fueron observadas conjuntamente con la playa. Con estos elementos se determinó la aloestratigrafía del sistema.

Como referencias morfológicas para correlación se observó los sistemas estuariales de Topocalma y Cáhuil (Fig. 1), cuya estructura es parecida a la de Pichilemu. Se visito además las terrazas estuariales de los sistemas Aconcagua, Cartagena, Maipo, Maule e Itata (Fig.1), debido a su similar composición sedimentaria y su relación con barras, flechas o barreras marinas. El sitio descrito por HERVÉ et al. (2003) en Algarrobo fue usado como importante referencia geocronológica, por tener un emplazamiento similar al de la terraza de Pichilemu. Estas localidades sirvieron de enlace para la correlación con los sectores relatados en los trabajos sobre geocronología, citados en la introducción.

\section{RESULTADOS}

\section{Los valles costeros: sus bordes (Fig. 2)}

Estos valles son principalmente dos, que convergen en uno solo al aproximarse a la ensenada en zeta de Pichilemu. Están emplazados en el sistema de terrazas costeras altas, cuyas generaciones son bien distintas a la del nivel de terraza baja de fondo de valle. Los flancos de valle son bordes de dos sistemas de terraza: TM1, con plataformas entre $\sim 10$ y $50 \mathrm{~m}$ de altitud y TM2, con plataformas principales entre 80 y más de $100 \mathrm{~m}$ de altitud. Su cuerpo consiste litologicamente en esquistos del basamento en la base y en sedimentos marinos y é́licos hacia la superficie. La caracterización detallada de estos materiales está fuera del marco de este trabajo. Morfológicamente, la terraza TM 1 se conserva más intacta que TM 2 , notoriamente más disectada.

\section{Terraza Te: composición (Fig. 2)}

Esta forma corresponde al nivel del fondo plano de los valles y se extiende hasta poco más de $5 \mathrm{~km}$ hacia el interior en el valle más largo. Sus mayores anchuras son de 0.3 a 0.5 


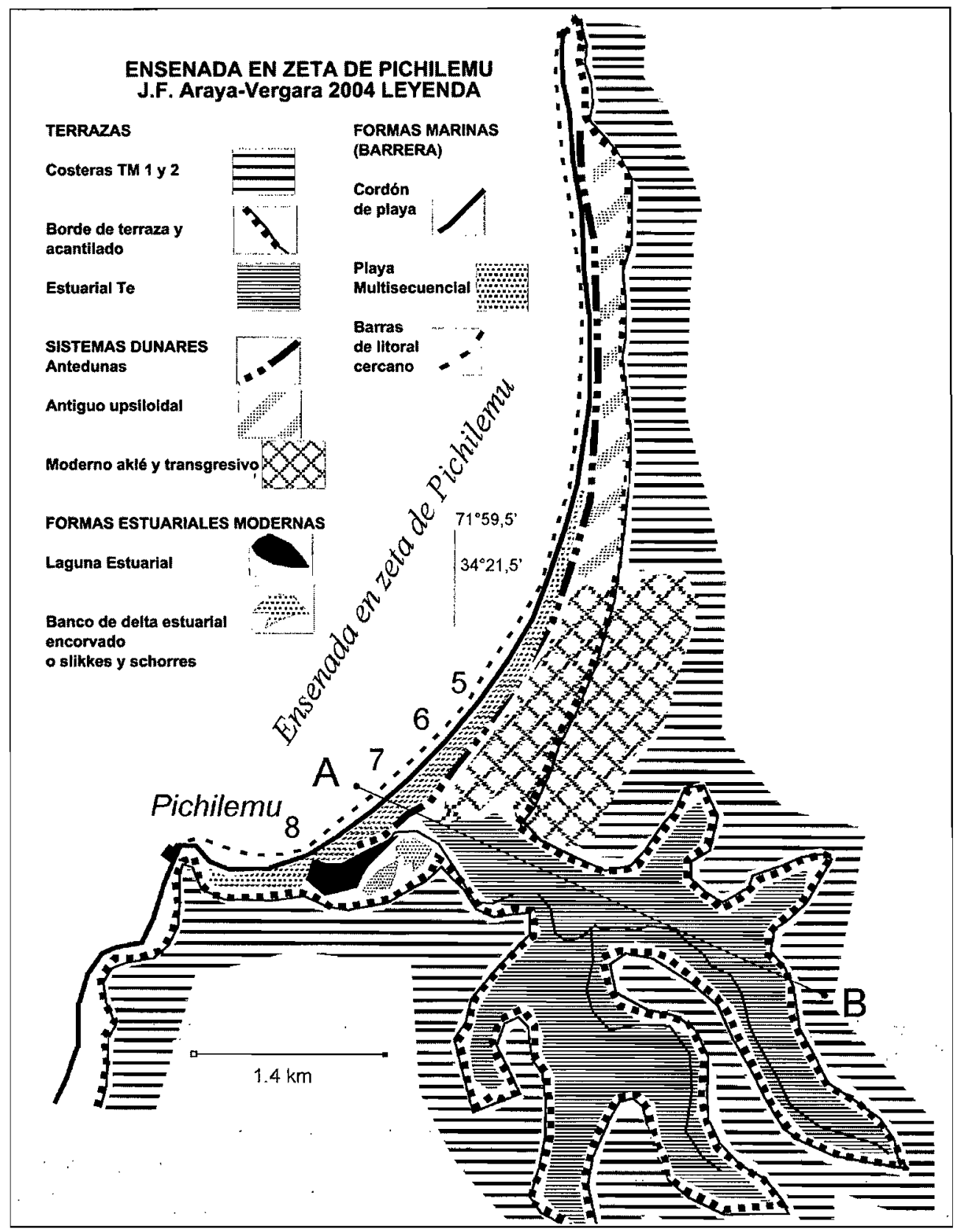

Fig. 2. Mapa geomorfológico del sistema de Pichilemu. Linea A-B = corte de Fig. 8. Números en línea litoral = ubicación de perfiles de playa citados en el texto

Fig. 2. Geomorphological map of the Pichilemu system. Line A-B = cross section of Fig. 8. Numbers in shoreline $=$ location of beach profiles cited in the text. 
$\mathrm{km}$ en los valles confluentes y hasta $0.75 \mathrm{~km}$ aguas abajo de la confluencia. Se trata de una forma casi intacta (Figs. 3 a 8), con superficie plana. Sus propiedades de altitud y estructura sedimentológica están indicadas en la Fig. 4 y la Tabla 1. Su altitud no es siempre la misma que se deduce de la Fig. 4. Ella puede alcanzar $2.5 \mathrm{~m}$ o más hacia el interior, en cambio sólo $1.5 \mathrm{~m}$ hacia el mar junto a la laguna estuarial. Esto significa que la superficie no es totalmente horizontal. La estructura sedimentológica de la escarpa muestra lo siguiente (Figs. 3 a 6 y Tabla 1):

a) La secuencia inferior consiste en multicapas laminares, cuyas subcapas revelan diferencias de consistencia. Las más consistentes sobresalen en el corte, indicando una textura más fina que la de las entrantes. Debe entenderse que la Tabla 1 indica aproximadamente sólo la granulometría media de la secuencia, $\sin$ especificar las subcapas. La subcapa fina de cada lámina tiene un comportamiento sensiblemente plástico y puede ser calificada como arena-limo-arcilla. La consistencia de la secuencia resulta baja, porque en terreno fue medida en húmedo. En seco, las subcapas finas debe ser las más consistentes de todo el corte, porque se expresan como salientes, rasgo típico de capas resistentes. Si la subcapa fina corresponde a la parte superior de cada capa, ésta es resultado de sedimentación gradual. El conjunto corresponde a ritmitas formadas en ambiente de sedimentación de fondo lagunar, a una profundidad tal, que independizó el desarrollo del proceso rítmico con respecto a turbulencias externas de origen fluvio-marino. Así, el techo de esta secuencia debe haber constituido una superficie original bastante horizontal. Aunque en el presente esta condición tiende a conservarse, se observa un leve basculamiento de diferentes secciones, 0.5 $-2^{\circ}$, tanto hacia el mar como hacia el interior. En un tramo aguas arriba del representado por la Fig. 4, se pasa a una superficie rugosa de este techo, debida a la disección discontinua de algunas ritmitas superiores. Ésta ha producido la remoción local de dos o tres capas hasta una profundidad decimétrica.

b) La capa media se desarrolla sobre la discordancia que representa el techo de la secuencia inferior. Es tratada como una sola capa, puesto que contiene diastemas discontinuas poco reconocibles. Éstas representan quizás un ambiente sedimentario parálico. Como en la terraza homóloga de Cartagena (Fig. 1), ellas pueden manifestarse en estructuras de estratificación cruzada planar, con multicapas muy delgadas difíciles de ver detalladamente en Pichilemu, pero

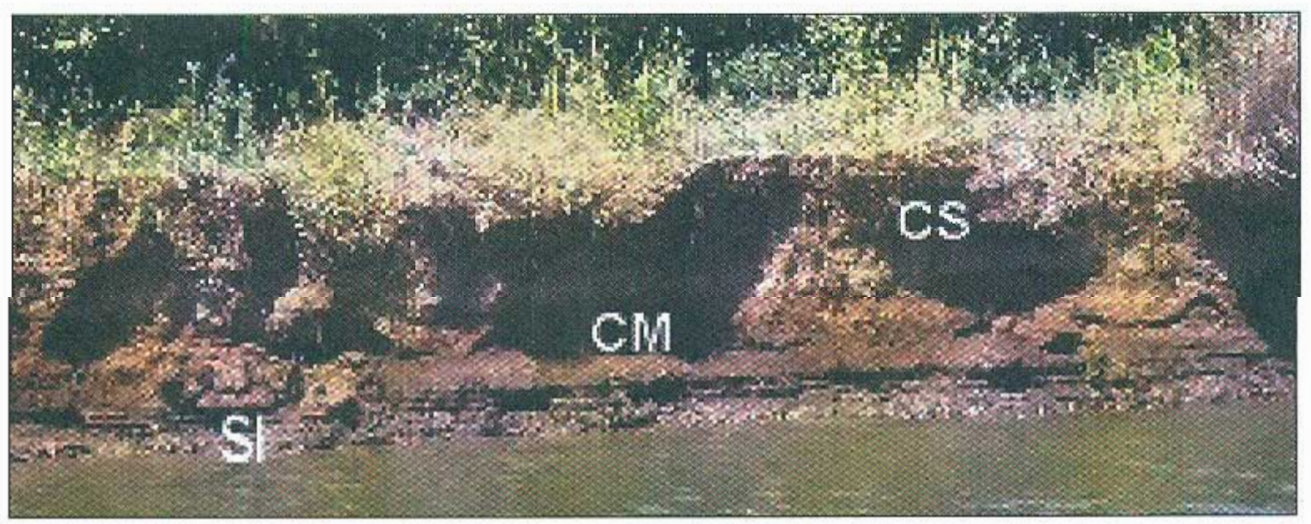

Fig. 3. Terraza Te: Escarpa que muestra: $\mathrm{SI}=$ secuencia inferior; $\mathrm{CM}=$ capa media; $\mathrm{CS}$ = capa superior.

Fig. 3. Terrace Te: Scarp showing: $\mathrm{SI}=$ lower sequence; $\mathrm{CM}=$ intermediate bed; $\mathrm{CS}=$ upper bed. 


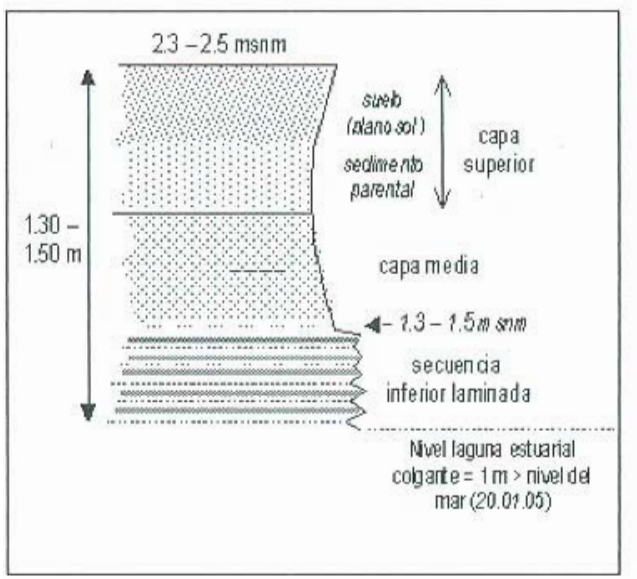

Fig. 4. Terraza Te: Escarpa de orilla meándrica cóncava; estructura sedimentaria, perfil y referencias altimétricas (ver Tabla 1)

Fig. 4. Terrace Te: Scarp of concave meandric curve; sedimentary structure, profile and altimetric references (see Table 1). fáciles de apreciar en Cartagena, en la unidad estratigráfica homóloga. El aspecto rojizo del conjunto no corresponde a oxidación in situ post-deposicional, puesto que la sesquioxidación sólo es observable en la matriz fina (arcillas), y no en las arenas. Consecuentemente, este cuerpo debe haber sido depositado con una carga fina previamente oxidada. Su base sobreyace acondicionándose a la topografía superficial de la secuencia inferior, sea ésta lisa o con rugosidades debidas a remociones localizadas. En este último caso, las diastemas discontinuas están plegadas hacia la base, lo que hace asumir que la acomodación a la microtopografía se realizó mediante pliegues de fondo de distinto radio de curvatura, con longitudes de onda variables entre algunos decímetros y unos $3 \mathrm{~m}$. Puede verse también algunas diastemas plegadas en pequeño radio de curvatura sobre la superficie lisa de la secuencia inferior. En este caso, ellas pueden atribuirse a pliegues de cobertura, independien-

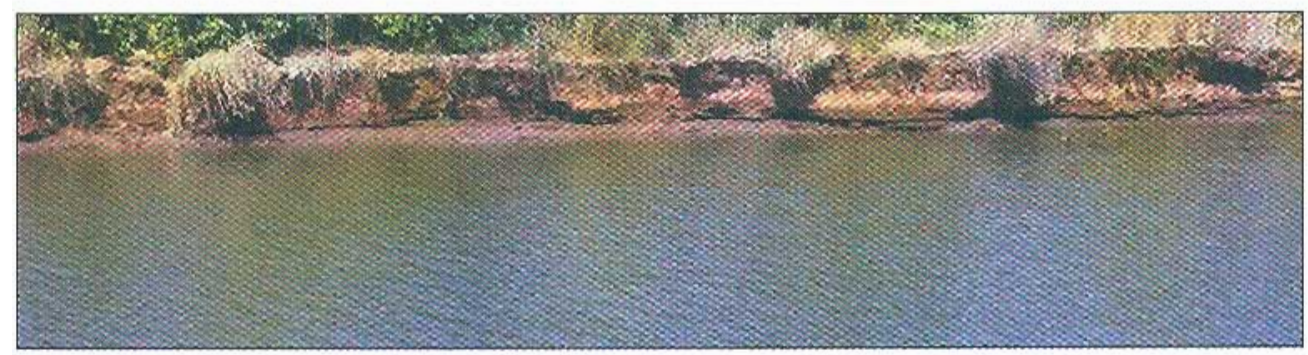

Fig. 5. Terraza Te: vista panorámica, mostrando algunos rasgos de deformaciones microtectónicas en unidades sedimentarias.

Fig. 5. Terrace Te: panoramic view, showing some features of microtectonic deformations in sedimentary unities.

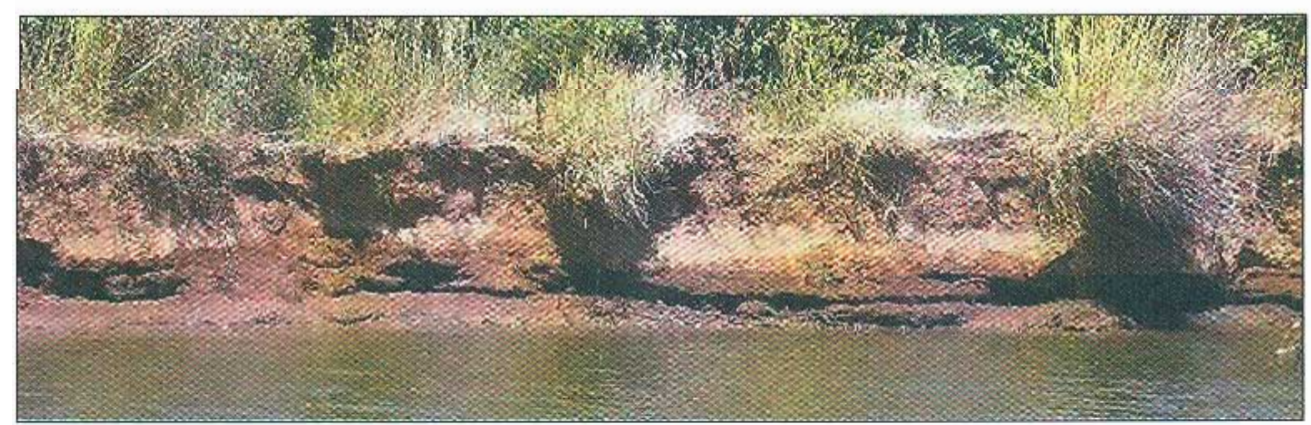

Fig. 6. Terraza Te: otra vista panorámica mostrando deformaciones en capas.

Fig. 6. Terrace Te: another panoramic view, showing deformations in beds. 
Tabla 1. Estructura sedimentaria y sedimentos de la terraza Te. Ver Fig. 4. Table 1. Sedimentary structure and sediments of the terrace Te. See Fig. 4.

\begin{tabular}{|c|c|c|c|c|c|c|c|c|c|}
\hline \multirow[t]{2}{*}{ Capa } & \multirow[t]{2}{*}{$\begin{array}{c}\text { Espesor } \\
\mathrm{cm}\end{array}$} & \multirow[t]{2}{*}{$\begin{array}{c}\text { Estructura } \\
\text { sedimentaria }\end{array}$} & \multirow[t]{2}{*}{ Textura } & \multicolumn{2}{|c|}{$\begin{array}{l}\text { Consistencia } \\
\text { kgcm2-1 }\end{array}$} & \multirow{2}{*}{$\begin{array}{c}\text { Color } \\
\text { Munsell } \\
\text { en seco }\end{array}$} & \multirow{2}{*}{$\begin{array}{l}\text { Forma } \\
\text { granos } \\
\text { arena }\end{array}$} & \multirow{2}{*}{$\begin{array}{c}\text { Textura } \\
\text { superficial } \\
\text { granos } \\
\text { arena }\end{array}$} & \multirow[t]{2}{*}{ Alteraciones } \\
\hline & & & & Seco & Húmedo & & & & \\
\hline $\begin{array}{c}\text { Superior } \\
\text { (suelo) }\end{array}$ & $\sim 30$ & $\begin{array}{c}\text { Blocosa } \\
\text { (pedológica) }\end{array}$ & $\begin{array}{l}\text { Arena media } \\
\text { a fina limosa }\end{array}$ & $>4.5$ & - & $\begin{array}{c}\text { Gris } \\
5 Y R 5 / 1\end{array}$ & $\begin{array}{c}\text { Sub } \\
\text { Redondeada } \\
\mathbf{a} \\
\text { subangulosa }\end{array}$ & Mate & $\begin{array}{l}\text { Sesquioxidación } \\
\text { baja en arcillas }\end{array}$ \\
\hline $\begin{array}{l}\text { Superior } \\
\text { (sedimentos) }\end{array}$ & 30 & Masiva & Id. & $>4.5$ & - & $\begin{array}{c}\text { Gris } \\
\text { 5YR6/1 }\end{array}$ & - & Id. & Id. \\
\hline Media & 40 & $\begin{array}{c}\text { Masiva a sub- } \\
\text { lagunar } \\
\text { (grumosa en el } \\
\text { detalle) }\end{array}$ & $\begin{array}{c}\text { Arena-limo- } \\
\text { arcilla }\end{array}$ & $\begin{array}{c}\text { Parte } \\
\text { super. } 4 \\
4.5\end{array}$ & $\begin{array}{c}\text { Parte } \\
\text { inferior } \\
1.3-2.2\end{array}$ & $\begin{array}{l}\text { Pardo } \\
\text { rojizo } \\
5 Y R 5 / 3\end{array}$ & $\begin{array}{c}\text { Sub } \\
\text { redondada }\end{array}$ & Mate & $\begin{array}{l}\text { Sesquioxidación } \\
\text { alta en arcillas } \\
\text { rojizas }\end{array}$ \\
\hline $\begin{array}{c}\text { Secuencia } \\
\text { inferior }\end{array}$ & $\begin{array}{l}\text { Visible } \\
30-50\end{array}$ & $\begin{array}{c}\text { Rítmica: estratos } \\
\text { laminados, } \\
\text { espesor } \sim 6 \mathrm{~cm} \\
\text { c/u }\end{array}$ & $\begin{array}{l}\text { Arena limosa } \\
\text { a arena- limo- } \\
\text { arcilla }\end{array}$ & - & $\begin{array}{c}<1.3, \\
\text { tendencia } \\
\text { plástica } \\
\text { en } \\
\text { láminas } \\
\text { finas }\end{array}$ & $\begin{array}{c}\text { Pardo a } \\
\text { pardo } \\
\text { oscuro } \\
7,5 Y R 4 / 4\end{array}$ & $\begin{array}{c}\text { Sub } \\
\text { Redondeada } \\
\text { a } \\
\text { subangulosa }\end{array}$ & $\begin{array}{l}\text { Mate a brillo } \\
\text { natural en } \\
\text { arenas de } \\
\text { esquistos }\end{array}$ & $\begin{array}{c}\text { Sesquioxidación } \\
\text { media en } \\
\text { arcillas }\end{array}$ \\
\hline
\end{tabular}

tes de la forma del fondo o discordancia. La discordancia que separa la capa media de la superior es lisa y sensiblemente horizontal donde no hay pliegues de fondo y con rugosidades donde los hay. Pero no siempre las rugosidades superiores imitan los elementos de los pliegues de fondo. Otras, especialmente las de menor longitud de onda, tienen distribución anárquica, de lo que se deduce que han sido producidas por disección superior de la unidad.

c) La capa superior se acomoda bien tanto a las partes planas como a las rugosas de la discordancia que la separa de la capa media. A pesar de esta condición, la forma de su límite superior es plana (superficie de la terraza) y no guarda relación morfológica con la discordancia del fondo; presenta cierta rugosidad dispersa que puede interpretarse como resultado de disección con talwegs de profundidad decimétrica. Considerada como una sola capa de estructura masiva, las diastemas dentro de ella son conjeturales. El material sedimentario es parental con respecto al suelo, porque el límite entre ambos es gradual.
Este suelo limoso puede considerarse como un planosol, a pesar de la inseguridad de encontrar diastemas que controlen la parte inferior del perfil.

La generalizada textura superficial mate en los granos de arena de las tres unidades relatadas, teniendo en cuenta la presencia de granos subredondeados entre los subangulosos, indica que su desgaste ha sido dominantemente por abrasión, ya que la ausencia de pulimiento señala nula o escasa influencia del medio acuático sobre el mecanismo de desgaste. Los brillos observados en arenas de la secuencia inferior son naturales, no debidos a pulimiento, y corresponden a fragmentos líticos de los esquistos (p. ej.con biotita) que caracterizan regionalmente el cinturón costero.

\section{Disección de Te (Figs. 2 y 7 a 10)}

Esta terraza está disectada en meandros incididos. Aquí se da esta denominación a los meandros cuyo atrincheramiento es moderado, delimitados por una escarpa de orilla cón- 


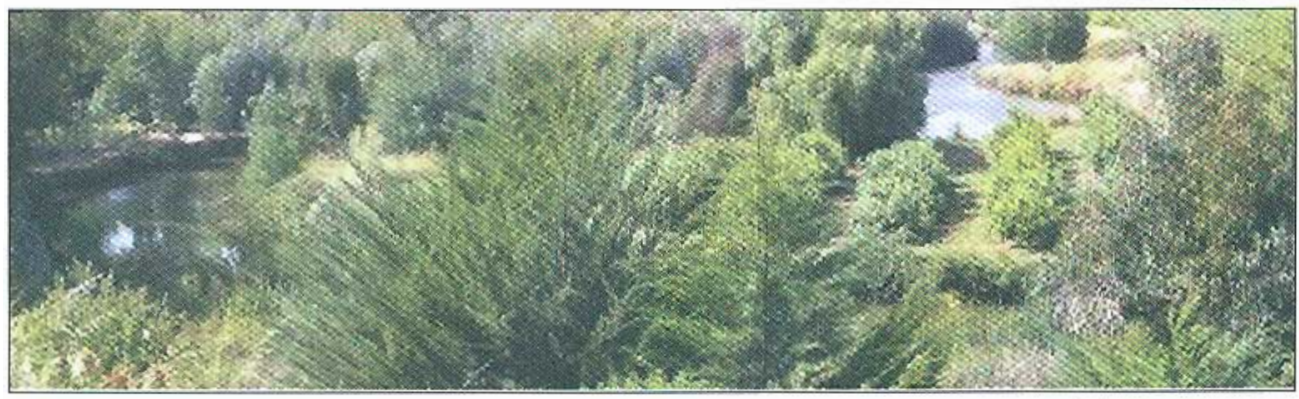

Fig. 7. Diseccion de la terraza Te: Meandro asociados a la laguna estuarial.

Fig. 7. Dissection of terrace Te: Meander associated to the estuarine lagoon.



Fig. 8. Disección de la terraza Te: Meandro angosto de características fluviales, aguas arriba de zona lagunar.

Fig. 8. Dissection of the terrace Te: Narrow meander of fluvial characteristics, upwaters of lagoonar zone.

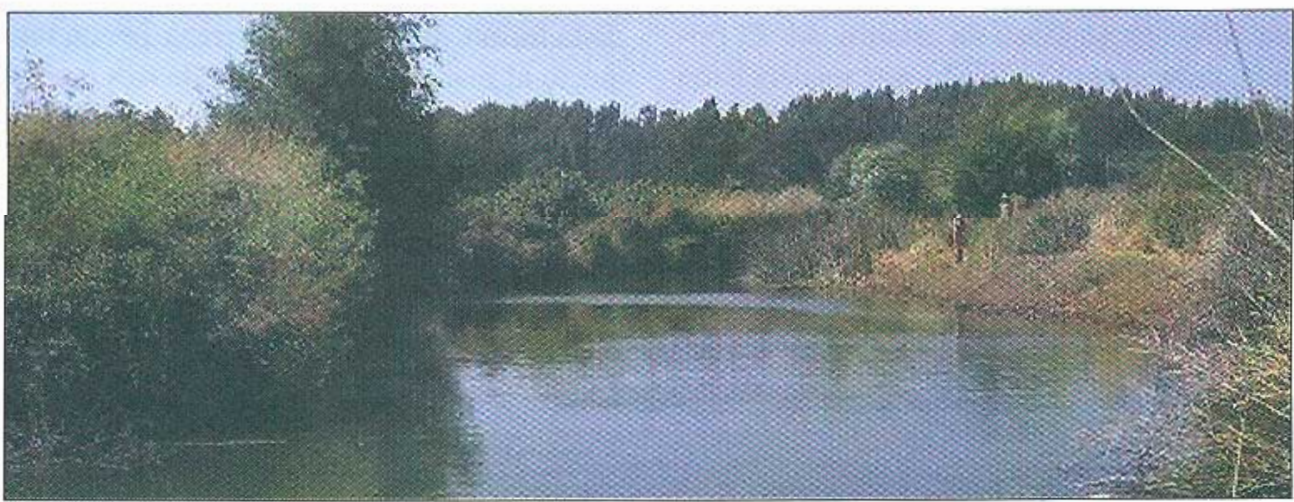

Fig. 9. Disección de la terraza Te: peldaño en el perfil transversal; rasgo de meandro crecido hacia adentro.

Fig. 9. Dissection of terrace Te: step in the cross profile; feature of ingrown meander. 


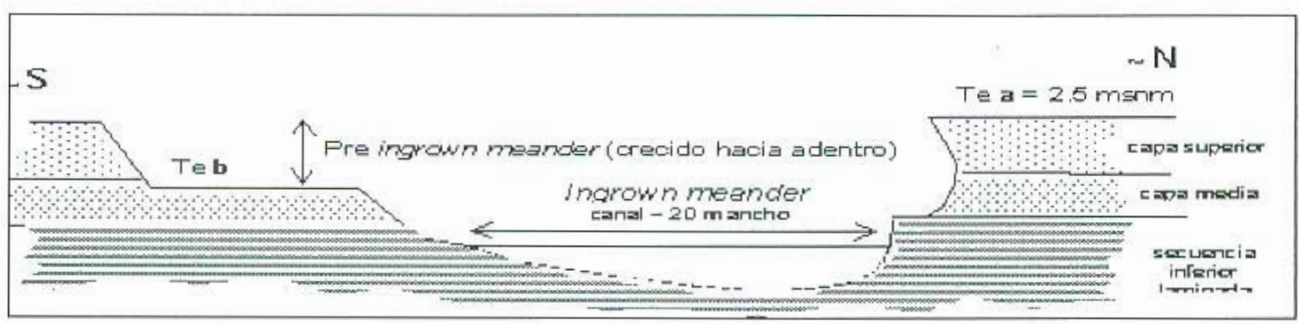

Fig. 10. Desección de Te: sección transversal que muestra el efecto de meandro crecido hacia adentro, abandonando el peldaño de terraza TM'b; la escala está distorsionada (ver Fig. 9).

Fig. 10. Dissection of Te: cross section showing the effect of ingrown meander, abandoning the terrace step TM'b; the scale is distorted (see Fig. 9).

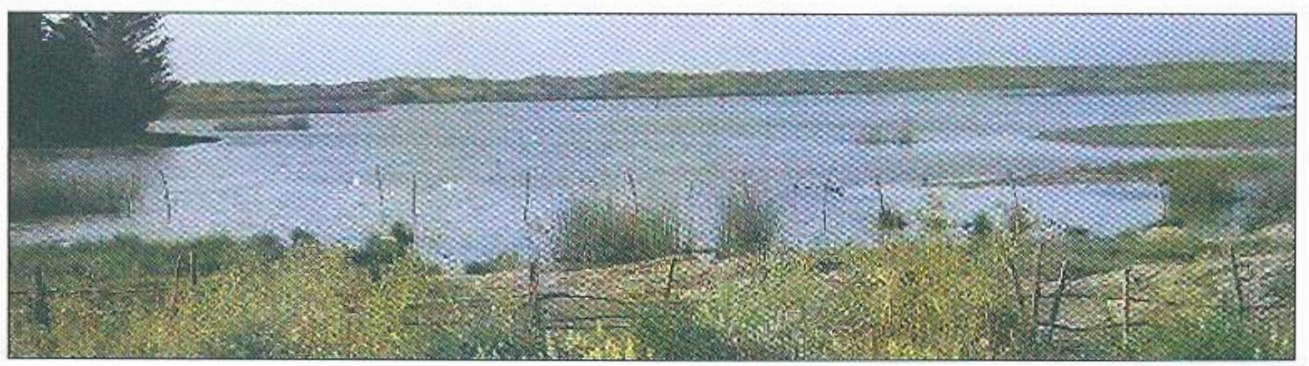

Fig. 11. Laguna estuarial cerrada (liman) . Al fondo, barrera.

Fig. 11. Closed estuarine lagoon (liman). At foreground, barrier.

cava cuya altura es poco más de la mitad de la altitud de la terraza (Fig. 4). Junto a las orillas convexas puede observarse un peldaño de rebajamiento de la terraza, típico de los meandros crecidos hacia adentro (ingrown meanders), indicando un desnivel métrico con respecto a la superficie principal. Esto debiera representar una incisión en dos tiempos, separados por un lapso de estabilidad. El primer tiempo está indicado por una incisión relativamente lenta, que permitió la erosión lateral, removiendo los sedimentos finos de la capa superior y parcialmente los de la capa media. El segundo tiempo se traduce en una tasa de incisión aparentemente mayor hasta afectar la secuencia inferior.

Formas marinas modernas (Fig. 2)

\section{Barrera (Fig. 11)}

Esta forma, que separa la terraza Te con respecto al mar, está compuesta de tres partes: el cordón de playa externo, la playa multisecuencial y los cordones de antedunas modernas.

\section{Tabla 2. Altitudes de la barrera referentes a la terraza estuarial (2 m)} TABle 2. Altitudes of the barrier With Reference to the estuarine terrace $(2 \mathrm{~m})$.

\begin{tabular}{|c|c|c|c|c|}
\hline $\begin{array}{c}\text { Perfil de estación } \\
(\mathbf{1 2 . 0 3 . 2 0 0 4 )}\end{array}$ & $\begin{array}{c}\text { Altitud máx. alta playa } \\
(\mathbf{m})\end{array}$ & $\begin{array}{c}\text { Diferencia con terraza } \\
\text { estuarial }(\mathbf{m})\end{array}$ & $\begin{array}{c}\text { Altitud del cordón más } \\
\text { alto de anteduna }(\mathbf{m})\end{array}$ & $\begin{array}{c}\text { Diferencia con terraza } \\
\text { estuarial }(\mathbf{m})\end{array}$ \\
\hline 5 & 1.73 & $\sim-0.27$ & 5.51 & $\sim 3.5$ \\
6 & 2.87 & 0.87 & 5.17 & $\sim 3.2$ \\
7 & 1.88 & $\sim-0.12$ & 5.01 & $\sim 3.0$ \\
8 & 0.53 & $\sim-1.47$ & 5.08 & $\sim 3.1$ \\
\hline
\end{tabular}




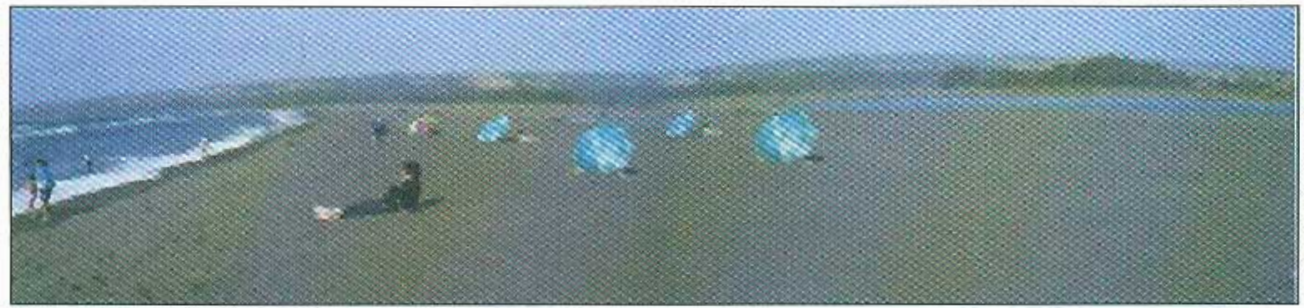

Fig. 12. Parte impersistente de la barrera que cierra el liman, el que está $1 \mathrm{~m}$ más alto que el nivel del mar (enero de 2005).

Fig. 12. Impersistent part of the barrier closing the liman, which is $1 \mathrm{~m}$ higher than sea level (january of 2005).

Se trata de la secuencia más externa de la playa, que se extiende continuamente junto a la línea litoral. De los perfiles transversales observados, la mayor parte consiste en la asociación entre cara de playa y berma (Fig. 3). Su papel es relevante frente a la laguna estuarial, porque forma parte de la barrera que durante la mayor parte del tiempo mantiene cerrada la boca del estuario. Comparando los perfiles de playa y duna anterior con la altitud de la terraza y laguna estuariales (Tabla 2; estaciones 5 a 8 en Fig. 2), se ve que la mayor altitud de la barrera con respecto a la terraza está dada por la duna anterior más alta (diferencia de ( $3 \mathrm{~m}$, Fig. 4). En cambio, el cordón de playa mismo puede estar sobre o bajo el nivel de la terraza (Fig. 5). Durante los breves períodos que siguen a la ruptura del cordón, la boca producida permite la formación de flechas encorvadas a ambos lados de la boca estuarial, debidas a la refracción del oleaje. En un lapso de marejadas invernales, en julio de 2004 se tuvo la oportunidad de observar un estado de post ruptura de la barrera ocurrida en junio. En julio, la boca estuarial estaba operando (Prof. M. Victoria Soto Bäuerle, Dep. de Geografía Universidad de Chile, 2004, comunicación personal), con muestra de ataque reciente de alta energía. Restos de las flechas encorvadas heredadas de las rupturas pueden permanecer en la ribera de la laguna, durante los prolongados lapsos de cierre, indicando incluso que ellas se formaron por más de un pulso de acreción de cordón de playa.

La arena de esta playa es totalmente distinta a las del cuerpo de la terraza Te (Tablas 1 y 3). Representa un trabajo largo en medio litoral con corriente de deriva y zonas de rompiente intermedia, reflejado en el notorio pulimiento que ha acompañado al desgaste de los granos. La gran proporción de minerales oscuros indica fuentes de abastecimiento lejanas, ubicadas en el basamento

\section{Tabla 3. Arenas del Cordón de playa eXterno de barrera y de las dunas aKLÉ} TABle 3. SANDS OF THE OUTER BEACH RIDGE OF BARRIER AND OF THE DUNES AKLÉ

\begin{tabular}{|c|c|c|c|c|c|}
\hline Forma & Textura & Color Munsell en seco & Forma granos & Textura superficial & Alteraciones \\
\hline $\begin{array}{c}\text { Cordón de playa } \\
\text { externo }\end{array}$ & Arena media & $\begin{array}{c}\text { Gris muy oscuro 10YR3/1 } \\
\text { predominio de } \\
\text { ferromagnesianos }\end{array}$ & $\begin{array}{c}\text { Subredondeados } \\
\text { a subangulosos }\end{array}$ & $\begin{array}{c}\text { Preferentemente } \\
\text { brillante }\end{array}$ & $\begin{array}{c}\text { Oxidaciones en } \\
\text { cuarzos }\end{array}$ \\
\hline Dunas aklé & Arena media a fina & $\begin{array}{c}\text { Gris oscuro10YR4/1 } \\
\text { ferromagnesianos menos } \\
\text { oscuros. Aumenta } \\
\text { proporción de minerales } \\
\text { claros }\end{array}$ & $\begin{array}{c}\text { Subredondeados } \\
\text { a subangulosos }\end{array}$ & $\begin{array}{c}\text { Mate a levemente } \\
\text { brillante }\end{array}$ & $\begin{array}{c}\text { Oxidaciones en } \\
\text { cuarzos }\end{array}$ \\
\hline
\end{tabular}




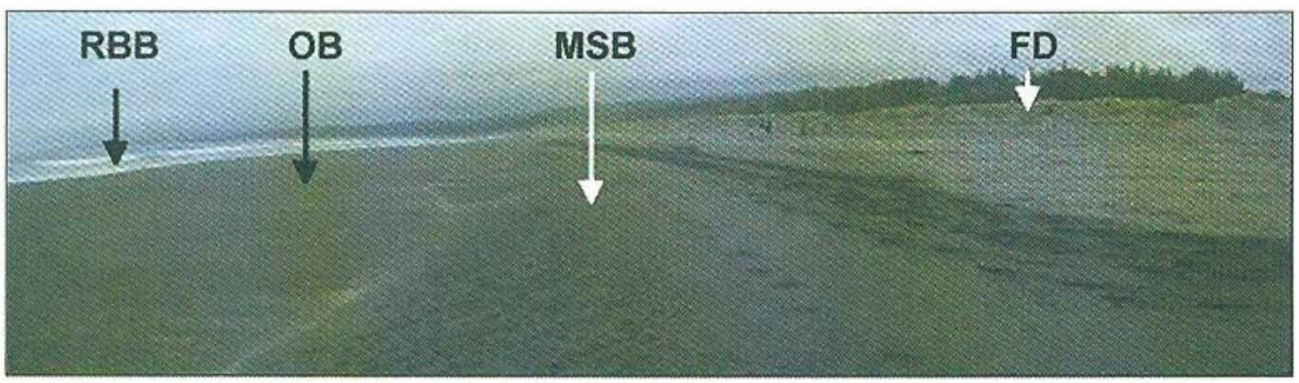

Fig. 13. Partes del perfil de playa y antedunas en la zona media de la ensenada (marzo, 2004). $\mathrm{RBB}=$ litoral cercano con barra y playa rítmicas; $\mathrm{OB}=$ cordón de playa externo; $\mathrm{MSB}=$ playa multisecuencial; $\mathbf{F D}=$ anteduna.

Fig. 13. Parts of the beach profile and foredunes in the middle zone of the embayment (march, 2004). $\mathrm{RBB}=$ nearshore's rhythmic bar and beach; $\mathrm{OB}=$ outer beach ridge; $\mathrm{MSB}=$ multisequential beach $=\mathrm{FD}=$ foredune.

esquistoso de la región y aún posiblemente en áreas de volcanitas andinas. Los cuarzos y vidrios volcánicos que pueda encontrarse aparecen como elementos accesorios.

\section{Playa multisecuencial (Fig. 13)}

Analizando los perfiles de playa, lo más fre- cuente es que, detrás del cordón externo, haya una multisecuencia que representa un proceso de acreción. Ello señala continuidad secuencial de más de un cordón de playa, lo que realza el efecto de barrera que puede producir el conjunto playal. Siendo éste multisecuencial, refuerza la permanencia de los cordones de duna anterior alta (Fig. 14),

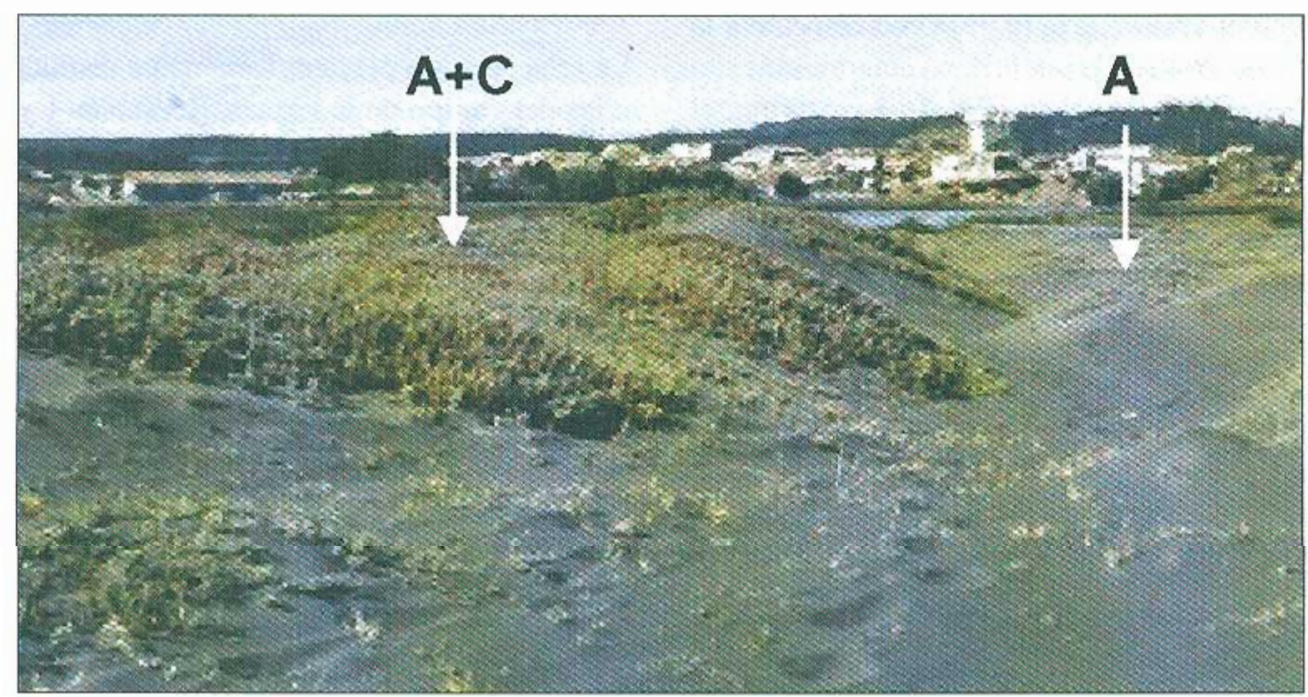

Fig. 14. Acreción de antedunas en la barrera: $\mathrm{A}+\mathrm{C}=$ cordón alto con Ambrosia chamissonis y Carpobrotus aequilaterus; $\mathrm{A}=$ cordón bajo externo solamente con Ambrosia. Al fondo, laguna estuarial (febrero, 1995).

Fig. 14. Accretion of foredunes in the barrier: $\mathrm{A}+\mathrm{C}=$ high ridge with Ambrosia chamissonis and Carpobrotus aequilaterus; $\mathbf{A}=$ outer low ridge only with Ambrosia. Background, estuarine lagoon (february, 1995). 


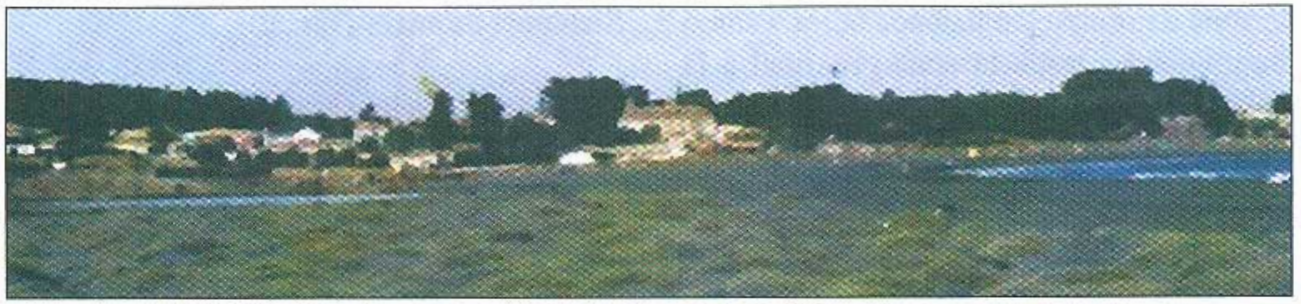

Fig. 15. Barrera que represa la laguna estuarial. EI nivel del mar está más alto que el de la laguna (febrero, 1995).

Fig. 15. Barrier damming the estuarine lagoon. The sea level is higher than the lagoon one (february, 1995).

dejando a la superficie de la terraza estuarial Te en situación de depresión topográfica (Fig. 15).

\section{Antedunas (Tabla 2)}

Las antedunas modernas están representadas hasta por 4 cordones, diferenciados por su altura, discernibles por estar separados por surcos interdunares y por la composición florística de la vegetación asociada (Fig. 14). De ellos, el más próximo a la playa puede estar o no presente, puesto que se compone de microdunas (parte notoriamente activa), cuya presencia no es continua a lo largo de la ensenada (Fig. 16).

\section{Barras de litoral cercano (Fig. 16)}

El sistema de barras, cambiante según el estado de la zona de rompiente, es representado simplificadamente en la Fig. 2. En él, la comparación de las diferentes generaciones de fotos aéreas y de éstas con lo observado en terreno muestra importantes cambios estructurales, dependientes de su orientación con respecto a los trenes de olas del mar de fondo operantes. Con mares de fondo del SW y del WSW interfiriéndose tiende a haber una barra principal, separada de la línea litoral por un surco, correspondiendo a la categoría

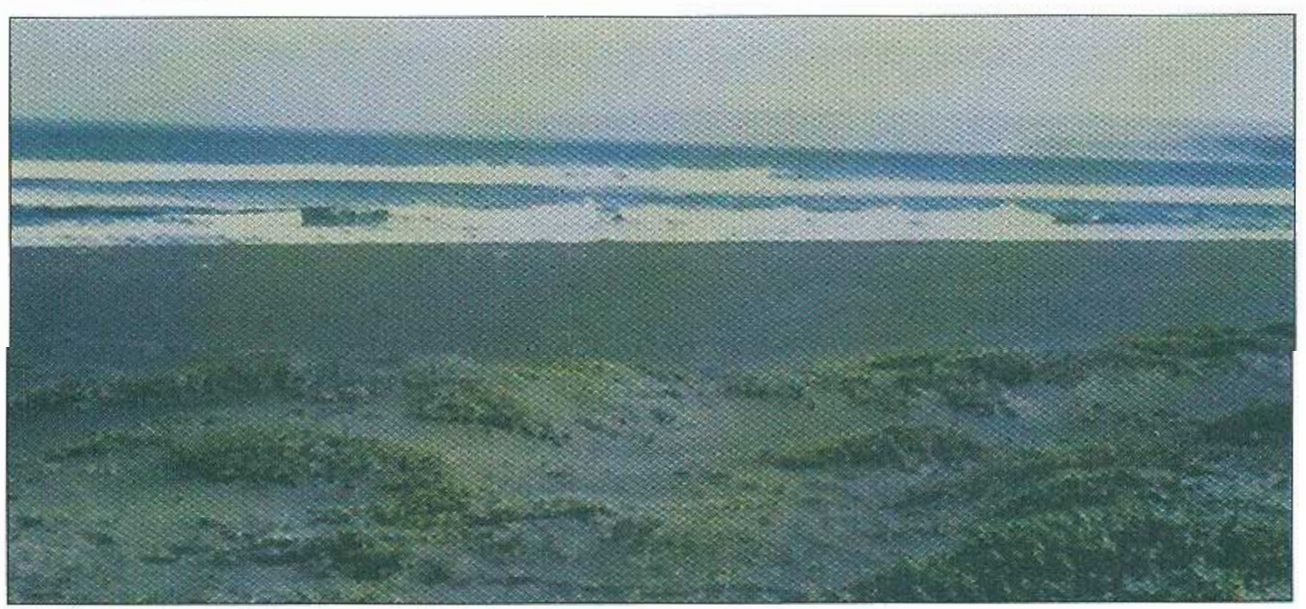

Fig. 16. Zona media de la ensenada: zona de rompiente disipativa (litoral cercano), con una barra principal y un canal; playa acrecional con microdunas (febrero, 1995)

Fig. 16. Middle zone of embayment: dissipative breaking zone (nearshore), with one alongshore main bar and one trough; accretional beach with microdunes (february, 1995). 
de zona de rompiente llamada barra y surco longitudinal. Desde la zona proximal a la distal de la ensenada hay gradación que va desde una zona más ancha con barra discontinua, a una más angosta, con barra continua. Este estado puede cambiar con interferencia balanceada entre mares de fondo del SW y del W, apareciendo barras rítmicas, o sea, discontínuas. Hacia el extremo distal, donde la exposición al mar de fondo del $\mathrm{W}$ es mayor, puede aparecer una transición entre barra rítmica y barra transversal (Figs. 13 y 17). Si se cruzan mares de fondo del SW y del WNW, las crestas refractadas de ambos pueden afectar la parte sur de la ensenada generándose playa reflectiva, estado en que la barra tiende a desaparecer. Al mismo tiempo, hacia la zona distal tiende a haber transición entre playa y barra rítmicas y barras transversales.

Estos estados de zona de rompiente indican operación de un monto considerable de sedimentos en el litoral cercano, asociado a la barrera supramareal. $\mathrm{Al}$ menos en las condiciones actuales, ésta debe recibir buen suministro de material del litoral cercano en los lapsos de acreción, compensando las pérdidas en los períodos de erosión.

\section{Sistemas dunares (Fig. 2)}

En este sistema hay esencialmente tres categorías de dunas: antedunas modernas junto a la playa, dunas de estructura aklé transgresivas (activas) y dunas parabólicas alargadas más antiguas.

Las antedunas modernas ya fueron descritas como asociadas al perfil de playa y, por lo tanto, a la barrera (Figs. 13 a 17).

Las dunas aklé son transgresivas sobre las terrazas Te y TM1 y constituyen dos mares de arena separados por el acantilado de TM1. El mar de arena sobre Te obedece a vientos SSW y es aklé-parabólico. El mar de arena sobre TM1 se debe a vientos SW y es también aklé-parabólico, pero generalmente con mayor longitud de onda. Ambos mares de arena presentan degeneración barjánica, debido a la influencia de vientos NNW. Cada unidad de tendencia barjánica afecta con mayor frecuencia a más de una onda del sistema parabólico. Debido a su lento funcionamiento, estas dunas han podido ser forestadas. Su arena es bien distina a las del cuerpo de la terraza Te (Tabla 1 y 3 ); es parecida a la de la playa; pero se le diferencia

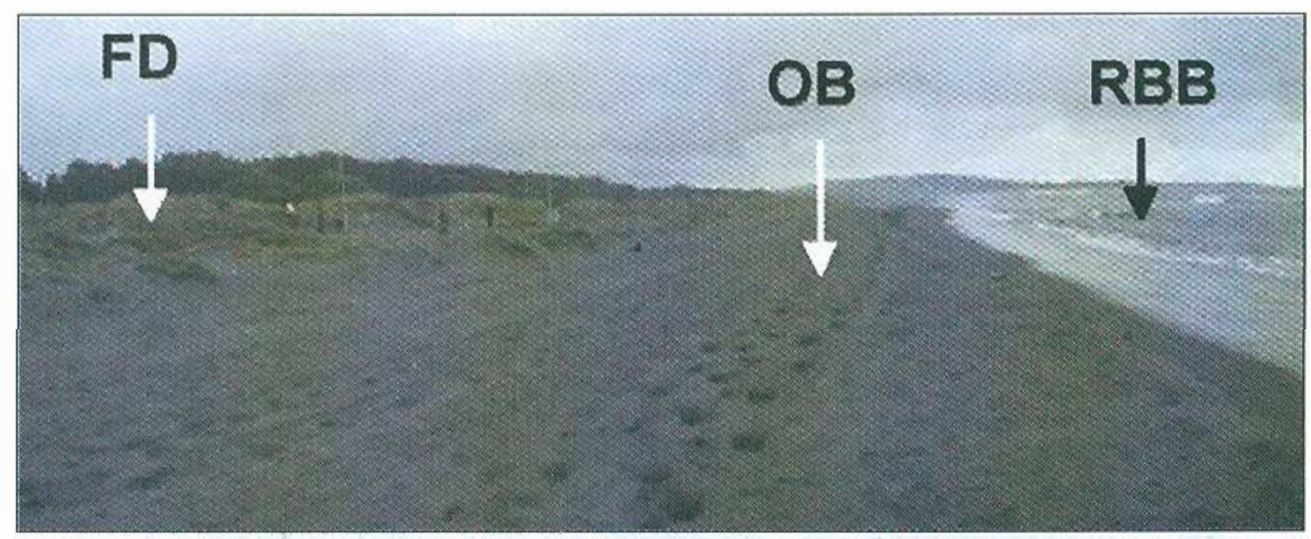

Fig. 17. Zona distal de la ensenada: $\mathrm{RBB}=$ barra y playa rítmicas de litoral cercano; $\mathrm{OB}$ $=$ cordón de playa externo $; \mathbf{F D}=$ dos cordones de anteduna.

Fig. 17. Distal zone of the embayment: $R B B=$ nearshore's rhythmic bar and beach; $O B$ $=$ outer beach ridge; $\mathrm{FD}=$ two ridges of foredune. 
por ser menos oscura, con mayor cantidad de minerales claros y mayor proporción de arena fina. Estas propiedades pueden interpretarse como efecto de selección granulométrica y rezago de minerales pesados en la remoción eólica desde la playa. Frente a esto, la texturas superficiales mates a poco brillantes de los granos deben corresponder a abrasión eólica sobre superficies previamente pulidas en el medio marino (despulimiento).

Las dunas antiguas se diferencian de las de los mares de arena modernos, porque son parabólicas alargadas a upsiloidales, formadas por vientos SSW y SW; y están aparentemente inactivas, vegetacionadas y asociadas a una sucesión florística inexistente en las dunas activas. Se cumple aquí lo observado en otros sistemas del litoral de Chile Central, en los que las dunas individuales de generaciones antiguas son más alargadas que las modernas, siendo comunes las parabólicas upsiloidales (observaciones inéditas).

\section{Formas estuariales modernas (Fig. 2)}

\section{Laguna estuarial (Fig. 11)}

Esta laguna permanece comunmente cerrada por la barrera. El espacio ocupado por ella puede variar notoriamente de acuerdo con las diferencias de caudal del río tributario. Si el caudal hace aumentar el volumen total mientras permanece cerrada, puede convertirse transitoriamente en un estuario cerrado colgante (perched closed estuary, expresión propuesta por COOPER 2001), debido a la altitud de la barrera. En enero de 2005 (21.01.05) su altitud era de $1 \mathrm{~m}$ sobre el nivel de marea media. En cambio, en febrero de 1995, estaba bajo el nivel medio del mar. En casos como éste, las formas estuariales circundando a la laguna son muy bajas, quizás deprimidas bajo el nivel medio del mar. Las depresiones resultantes de estos estados pueden corresponder a slikkes y schorres, aun cuando en estos sistemas micromareales su distinción es difícil. Por estas características, esta laguna estuarial corresponde a un liman.
Aunque en las fotografías aéreas y en las visitas a terreno se observe que la boca estuarial por ruptura del cordón de playa es un rasgo infrecuente, el proceso de ajuste post-ruptura puede ser deducido de ambas instancias de observación, por los restos de flechas encorvadas relatados al describir el cordón de playa. Se comprende así que la extención de la laguna puede variar desde el estado de estuario cerrado colgante al estado abierto. Entonces, puede llamarse con más precisión liman intermitente.

\section{Bancos encorvados de delta estuarial o slikkes y schorres}

Estos bancos pueden tener altitudes muy bajas; su forma es intermedia entre delta y flecha encorvada, como lo acusan los apéndices individualizados en el extremo externo del banco. Estas formas son impersistentes. Al menos en los detalles, pueden ser cubiertas en momentos de crecida o marejada, modelándose posteriormente. En esta parte del proceso deben aparecer como bancos de delta estuarial, debido la existencia de un canal estuarial de crecida entre los bancos y junto al borde de la terraza alta. Los lugares en que con mayor frecuencia puede extenderse la laguna estuarial, a partir de sus niveles más bajos, están a la altura del talweg de canales estuariales de crecida. Ellos son los lugares que pueden funcionar como slikkes y schorres.

La laguna estuarial, el delta estuarial con bancos encorvados y los ambientes de slikkes y schorres enseñan ambientes para diferentes facies y, por lo tanto, las estructuras que hipotéticamente pueden encontrarse en los sedimentos de $\mathrm{Te}$, anteriores a los procesos presentes.

\section{DISCUSIÓN}

\section{Formas actuales de la barrera como expres ión del balance de sedimentos}

En las condiciones presentes del caso de Pichilemu, al menos tres cordones de duna 
anterior más un cordón embrionario de microdunas indican un proceso de acreción moderno en las relaciones playa-duna. Según este comportamiento, es posible que cualquiera de las tendencias presentes del nivel del mar esté recubierta por la progradación debido a su mayor velocidad, causando aumentos de masa sedimentaria que mantienen emergido el sistema de cordón litoral a pesar del comportamiento del nivel del mar. Esto se puede comparar con las siguientes experiencias modeladas por PSUTY (1988): a un balance de masa débilmente negativo de la playa, responde un balance positivo de la duna asociada; a un balance equilibrado de la playa, responde un balance positivo de la duna, y a un balance fuertemente negativo de la playa, responde uno igualmente negativo de la duna.

\section{Influencia de la topografía pre-existente}

La explicación de la existencia de una barrera que ha podido represar el estuario debe buscarse considerando primero la topografía pre-existente. Si el desalineamiento costero explica en gran medida la forma en zeta de estas ensenadas (ARAYA-VERGARA 1983), este tipo de influencia se debe haber dado también en niveles más bajos del mar, durante un proceso transgresivo. DILLENBURG et al. (2000) examinaron la influencia de la topografía pre-existente mediante un modelo de barrera con translación de la cara de playa (Shoreface Translation Model, STM) en Río Grande do Sul. Ellos encontraron que este importante factor ha determinado el tipo de barrera litoral, pudiendo reconocerse barreras progradadas a lo largo de las entrantes y barreras con playas de tierra firme recesionadas frente a las salientes. Su análisis del balance de sedimentos señala que la mayor parte del material que progradó las entrantes provino de la plataforma continental. Una barrera puede ascender sobre el substrato trasladándose a medida que se produce la transgresión y, por lo tanto, entregando elementos transgresivos sobre la superficie de sedimentos lagunares del área represada. Ello puede determinar una interestratificación entre ambos tipos de ma- terial. Sin embargo, para Pichilemu, estos mecanismos no pueden entenderse si no se considara lo discutido en el punto siguiente.

\section{Estructuración de la barrera en función de una transgresión}

Si se considera la regla de Bruun, es difícil concebir que una barrera llegue a constituirse por acreción vertical durante el progreso de una transgresión. Según esa regla, el ascenso del nivel del mar es contrario a la mantención del cordón, porque la masa arenosa de éste pasa al litoral cercano. Pero hay experiencias que indican que la regla de Bruun funciona sin interferencias importates sólo si hay transporte por deriva longitudinal en estado estable, sin cambio neto de volumen de sedimentos en un área dada (SWIFT et al., en OTVOS 1982). Si el estado de la zona de rompiente cambia desde barra y surco longitudinal a barra y playa rítmicas con elementos de barra y surco transversal, puede haber transferencia de arena a la playa subaérea, favoreciendo su acreción y la formación de nuevas dunas anteriores. Si estos cambios de estado se han sucedido durante la transgresión, el sistema de cordón litoral puede haberse mantenido, pero eso depende del balance entre las velocidades relativas de progradación, de transgresión y de una eventual elevación tectónica.

Para enfocar adecuadamente el modo de interacción de estos tres procesos, puede revisarse primero la tendencia presente del nivel del mar. Análisis de FONSECA (1987) para un lapso de 40 años - entre 1945 y 1985 - indican ascenso del nivel del mar en Caldera y Talcahuano, con tendencia a equilibrio dinámico. Para Valparaíso, en cambio, se advierte equilibrio estable con oscilaciones (Fig. 1; Tabla 2, cifras deducidas de los gráficos de FONSECA 1987).

Comparando estos datos con series de la costa de Estados Unidos analizadas para el lapso 1900 - 1971 se ve que en la costa oriental (atlántica) las tasas de ascenso relativo del nivel del mar oscilaron entre $\sim 2.1$ y $5.7 \mathrm{~mm} /$ año; en cambio, en la costa pacífica occiden- 
Tabla 2. Cambios del nivel del mar durante 40 años (1945-1985) Table 2. Sea level Changes duRing 40 years (1945-1985)

\begin{tabular}{|c|c|c|c|c|}
\hline Puerto patrón & Ascenso total $(\mathrm{mm})$ & $\begin{array}{c}\text { Oscilación máxima } \\
(\mathrm{mm})\end{array}$ & $\begin{array}{c}\text { Tasa media deascenso } \\
(\mathrm{mm} / \mathrm{año})\end{array}$ & $\begin{array}{c}\text { Tasa media de } \\
\text { ascenso o descenso } \\
\text { (mm/año) }\end{array}$ \\
\hline $\begin{array}{c}\text { Caldera } \\
\text { Valparaíso } \\
\text { Talcahuano }\end{array}$ & -13 & - & $\sim 0.3$ & - \\
\hline
\end{tabular}

tal fluctuaron entre 1.89 y 1.95 (STAPOR, Jr. 1982). En esta última, una compilación de cinco estaciones de California (HICKS \& CROSBY 1974, en BLOOM 1979), para el lapso 1893-1972 (30 a 70 años según el caso), muestra ascenso en equilibrio dinámico metaestable para tres de ellas, estabilidad en equilibrio metaestable para una y descenso con equilibrio metaestable para la quinta. De esto resaltan tres tipos de observación: a) La tasa de ascenso del nivel marino es mayor en la costa atlántica que en la costa pacífica, lo que puede interpretarse como una mayor tendencia a elevación cortical en esta última, por ser costa tectónicamente más activa; b) los segmentos de línea de costa con tendencia al ascenso en la costa del Pacífico pueden estar separados por sectores con estabilidad o con descenso relativo del nivel del mar, lo que puede interpretarse como respuesta a comportamientos tectónicos diferenciales de la costa; y c) los rasgos de metaestabilidad, deducidos de la presencia de oscilaciones más fuertes que las más frecuentes, parecen ligados a rupturas de equilibrio que pueden ser cosísmicas.

Si los mismos tipos de observación se aplican a la costa central de Chile, se tiene: a) La tasa de ascenso del nivel marino es menor que la de la costa norteamericana del Pacífico, lo que puede interpretarse como resultado de una elevación cortical más activa, debida a que el proceso de coalisión entre las placas oceánica y continental es distinto al observado en Norteamérica; b) como en la costa norteamericana del Pacífico, coexisten segmentos de línea de costa con tendencia al ascenso y con tendencia a estabilidad, lo que puede interpretarse como respuesta a com- portamientos tectónicos diferentes de la costa; y c) los gráficos de FONSECA (1987) presentan también rasgos de metaestabilidad, representados por oscilaciones más fuertes que las más frecuentes, indicando tal vez rupturas cosísmicas.

Por no ser puerto patrón, Pichilemu carece de información que permita determinar cambios recientes del nivel del mar con la misma certeza que en los puertos patrones ya nombrados. Pero, interpolando con las referencias al Norte y al Sur, es probable que el nivel del mar en el lapso analizado haya cambiado manteniendo un equilibrio estable a dinámico en ascenso. Cualquiera de las dos tendencias debe ser entendida considerando los cambios en el Holoceno, a partir de modelos, como son las curvas de nivel del mar.

Once curvas de nivel del mar en el Holoceno seleccionadas por MÖRNER (1982), representando diversas costas del mundo, una lograda por PSUTY (1986) en N. Jersey y el modelo de CHURCH (en HERVÉ et al. 2003), indican fenómenos aproximadamente coincidentes (Tabla 3). Se deduce de esto que desde fines del Pleistoceno ( p. ej. 15000 A.P.) hasta aproximadamente el Holoceno Medio, la transgresión fue más rápida que desde esta edad hasta el presente. Si se toman los valores deducidos al aplicar el modelo de CHURCH (en HERVÉ et al. 2003), se ve que la tasa de ascenso de los últimos 2 a $3 \mathrm{Ka}$ es parecida a la que se desprende del análisis de FONSECA (1987) para lugares de la costa de Chile Central entre 59 y 19 años AP (Tabla 2). Esto permite suponer que la tendencia al ascenso en las tasas señaladas continúa en el presente. Asumiendo que la 
Tabla 3. Ascenso del nivel del mar en la Transgresión Flandesa vs. elevación TECTÓNICA

Table 3. Sea level rise during the Flandrian Transgressión vs. tectonic UPLIFT

\begin{tabular}{|c|c|c|c|c|c|}
\hline Autoridad & $\begin{array}{l}\text { Tasa de ascenso } \\
15.6 \mathrm{Ka}(\mathrm{mm} / \mathrm{a})\end{array}$ & $\begin{array}{l}\text { Depresión del nivel del } \\
\text { mar 7-6 } \mathrm{Ka} \mathrm{AP}(\mathrm{m})\end{array}$ & $\begin{array}{c}\text { Tasa de ascenso } \\
\text { últimos } 6 \mathrm{Ka} \\
(\mathrm{mm} / \mathrm{a})\end{array}$ & $\begin{array}{l}\text { Tasa de escenso } \\
\text { desde 2-3 Ka AP } \\
\text { (mm/a) }\end{array}$ & $\begin{array}{l}\text { Tasa de elevación } \\
\text { tectónica deducida } \\
\text { desde } 6.5 \mathrm{Ka} \mathrm{para} \\
\text { Chile Central (mm/a) }\end{array}$ \\
\hline $\begin{array}{c}\text { Selección } \\
\text { MÖRNER } \\
1982\end{array}$ & & $\begin{array}{c}-5-13 \\
\text { (valores centrales: }-7-9 \text { ) }\end{array}$ & & & \\
\hline $\begin{array}{l}\text { PSUTY 1986, } \\
\text { costa de N. } \\
\text { Jersey }\end{array}$ & $\begin{array}{c}\text { Antes de } 7 \mathrm{Ka}: \\
1.8-2.0\end{array}$ & $-8-9$ & & $1.0-1.2$ & $\begin{array}{l}\text { Hasta altitud de la } \\
\text { terraza estuarial: } 1.5- \\
2.5 \mathrm{~m} \text {. En el interior, } \\
\text { probablemente } \sim 4 \mathrm{~m} \text {. }\end{array}$ \\
\hline $\begin{array}{c}\text { Modelo de } \\
\text { CHURCH, en } \\
\text { HERVÉ et al. } \\
2003\end{array}$ & 10 & & 0.5 & $0.1-0.2$ & \\
\hline
\end{tabular}

depresión del nivel del mar entre 7 y $6 \mathrm{Ka}$ AP está expresada en valores confiables (Tabla 3), la diferencia entre ellos y la altitud de la terraza estuarial (considerada entre 2 y 4 m) para este lapso de tiempo, indica que la velocidad de elevación tectónica ha sido mayor que la de ascenso del nivel del mar. Por lo tanto, el proceso de transgresión ha sido contrarrestado por la elevación cortical y la altitud de la terraza estuarial debe ser explicada tectónicamente. Tanto el análisis de FONSECA (1987) como la discusión de HERVÉ et al. (2003), respectivamente, permiten aceptar que la tendencia transgresiva actual y la elevación tectónica se han realizado con oscilaciones, posiblemente correspondiendo a equilibrio dinámico en ascenso. Si esto es así, no se concibe fácilmente la destrucción de cordones litorales debida al proceso transgresivo y la regla de Bruun sólo puede ser aplicada con reserva, quizás más para oscilaciones que para el proceso general.

Consecuentemente, el crecimiento de la barrera de cordones litorales puede asumirse haber comenzado con niveles del mar más bajos que el actual. Si la reducción de la tasa de ascenso del nivel del mar favoreció transferencia de sedimentos desde el litoral cer- cano, debe haberse producido un balance de masa sedimentaria positivo. Las barreras deben haber crecido en volumen y altura, proporcionalmente al balance.

Relacionando estos tipos de escenario, experiencias compiladas por ORME (1988) indican que durante las transgresiones se generan condiciones inestables, las playas migran ascendiendo con respecto a la plataforma continental y un cordón complejo de dunas comunmente precede esta migración. Los estacionamientos del nivel del mar durante la transgresión promoverán acumulación de cordones de dunas in situ. La revisión aloestratigráfica de la relación playaanteduna (SHORT \& HESP 1999) indica que la suma de estas construcciones puede traducirse en barreras de altura y masa considerables.

Los tipos de comportamiento modelados por PSUTY (1988, ver comienzo de la discusión) y generalizados por ORME (1988) pueden ser posibles en el caso de Pichilemu, por los rasgos de acreción observados y la tendencia a ascenso tectónico, que puede tener incidencias co-sísmicas, según análisis de HERVÉ et al. (2003). 


\section{Significado de la estructura sedimentaria de la terraza Te}

Trabajos anteriores permiten deducir los ambientes de sedimentación y las facies heredadas en el proceso de relleno del estuario en una ría (ARAYA-VERGARA 1981; ROY et al. 1980, NICHOL 1991, DALRYMPLE et al. 1992, ROY 1994, en ANTHONY et al. 2002). Desde la zona fluvial hacia el mar se puede reconocer una zonación tripartita de litofacies en costa dominada por el oleaje: delta fluvio estuarial, cuenca de fango central y boca estuarial de dominio marino. En un estuario de este tipo, en el litoral de Benin, ANTHONY et al. (2002) hallaron que este modelo en general se cumple. No obstante, se puede precisar que, si la boca estuarial está cerrada la mayor parte del tiempo, es porque la descarga fluvial es baja y la deriva litoral de sedimentos, relativamente fuerte. En el caso de la ensenada de Pichilemu, los estados más frecuentes de zona de rompientes, que reflejan la estructuración de las barras del litoral cercano, indican que la corriente de deriva y la deriva de sedimentos deben ser importantes. En estas condiciones, el material de relleno tras-barrera, que explica la terraza estuarial, debe ser esencialmente de origen fluvial, aunque provenga de cuencas relativamente pequeñas. La secuencia inferior de ritmitas indica que ellas deben haberse formado a una profundidad suficientemente grande, como para permitir el proceso rítmico sin influencia de turbulencias externas. Por lo tanto, lo fundamental del relleno trasbarrera es un terraplenamiento lagunar, desarrollando el cuerpo de una terraza de



Fig. 18. Construcción y disección de Te. Fase de terraplenamiento: 1 = laguna estuarial con sedimentos lagunares de fondo (a); 2 = relleno en ambiente parálico (b) en 0 cerca del nivel del mar. Fase de estabilidad: 3 = glacis de ahogamiento subaéreo (c); 4 = primera disección en meandros; 5 = segunda disección en meandros crecidos hacia adentro.

Fig. 18. Construction and dissection of Te. Phase of embanking (terracing): $1=$ estuarine lagoon with bottom lagunar sediments (a); 2 = filling in paralic environment (b) at or near sea level. Phase of stability: 3 = subaerial drowning glacis (c); $4=$ first dissection by meandering; 5 = second dissection by ingrown meandering. 
terraplenamiento (Fig. 18, 1 y 2 a, b), en el mismo tipo de emplazamiento que el fango central de los estuarios abiertos, pero manifestado en facies lagunares, como las relatadas por MARTIN et al. (1993). En cambio, la capa media (Fig. 4), que sobreyace a la secuencia lagunar, muestra una ruptura de equilibrio expresada primero por pequeños rasgos de disección del techo de la secuencia inferior, lo que indica el fin de la etapa de terraplenamiento lagunar. Esto parece corresponder al umbral de profundidad crítica en que un depósito de turbidez ya no puede expresarse en capas laminares. Esta capa media debiera corresponder a un drenaje en pequeños canales altamente anastomosados en materiales finos, funcionando posiblemente en un ambiente parálico (Fig. 18, 2b), con importante turbidez específica de arcilla oxidada. Ésta parece haber sido suministrada por los esquistos meteorizados de la cuenca interior. Es probable que este funcionamiento se haya realizado de modo parecido a lo que ocurre en el actual delta estuarial del Bío-Bío (teniendo en cuenta las diferencias de escala), donde aparecen densos conjuntos de pequeños bancos romboidales cuando hay bajas aguas y sobrecarga de sedimentos finos: Se trata de un anastomosamiento del estuario, en un estilo prácticamente fluvial. Si la operación del liman de Pichilemu ha sido a modo de un liman intermitente, la constitución de bancos de anastomosamiento debe haber sido impersistente, por diferencias de la dinámica estuarial parálica. En consecuencia, puede comprenderse la imperfección de la estratificación entrecruzada planar, por la discontinuidad espacio-temporal de bancos de anastomosamiento típicos. Hasta aquí, se trata de la última fase de terraplenamiento (terraplenamiento parálico?). Finalmente, la capa superior, más masiva, indica un probable ambiente sub-aéreo de deposición. Como la superficie tiene una leve pendiente hacia el mar (Te) y los sedimentos son finos, es probable que se trate de un cuerpo deltaico construido mediante el mecanismo de la arroyada, frenada por el efecto de represa provocado por la barrera litoral. Puede tratarse entonces de un glacis de ahogamiento (Fig. 18, 3c). Si este funcionamiento fue en la zona de influencia del lecho de arroyada, el cuerpo sedimentario corresponde a la fase de construcción de la terraza de estabilidad, cuyo material es inmediatamente anterior a la disección de Te. El criterio para definir terraza de estabilidad consiste en el reconocimiento de facies de fin de terraplenamiento y distintas a las de éste; debe poder ser usado para ambientes estuariales, lacustres y - en general - parálicos, además de los propiamente fluviales.

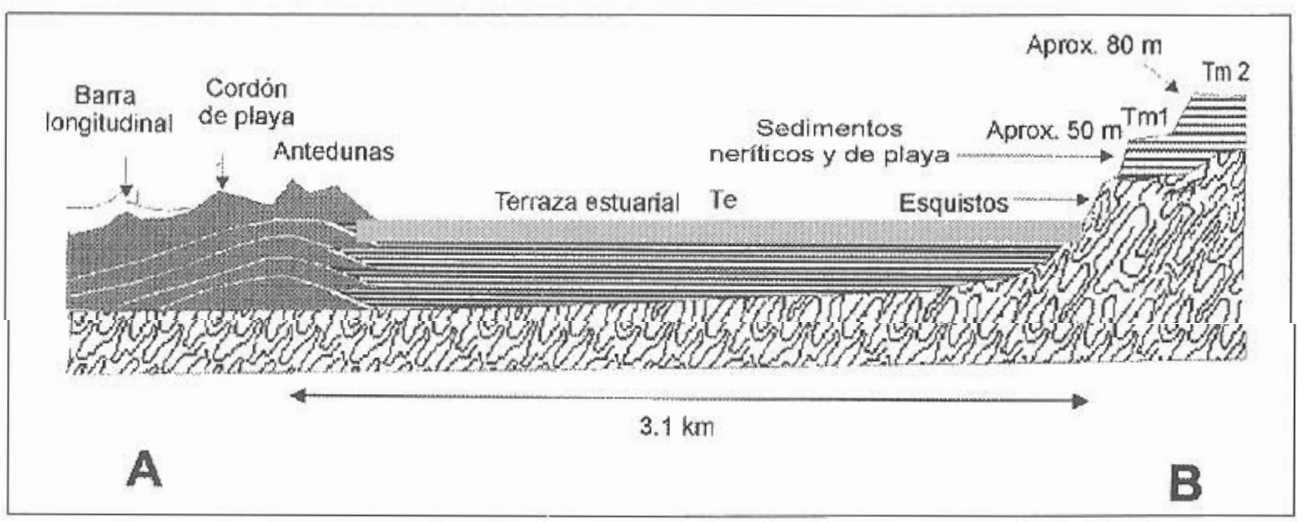

Fig. 19. Corte generalizado entre las terrazas (TM1y TM2) y el mar. Ver posición de A y B en Fig. 2.

Fig. 19. Generalized cross-section between the terraces (TM1 and TM2) and the sea. See location of A and B in Fig. 2. 
De acuerdo con lo anterior, la Fig. 19 constutiye una aproximación a la aloestratigrafía en el sistema estuarial y ensenada en zeta de Pichilemu.

\section{Significado del estilo de disección de la terraza Te (Fig. 18, momentos 4 y 5).}

Las diferencias de velocidades de incisión representadas por los meandros crecidos hacia adentro (ingrown meanders) pueden deberse al balance entre los mecanismos eustático y diastrófico. La fase pre - ingrown puede indicar un lapso en que las tasas de solevantamiento tectónico y de ascenso eustático eran poco diferentes, pero también influencia de un lapso de estabilidad. En cambio, la fase ingrown parece debida a un aumento de la tasa de elevación tectónica, rompiendo el equilibrio que condicionó la estabilidad.

\section{El papel de las crecidas y de las marejadas}

La observación de terreno indica que la ruptura de la barrera estuarial parece producirse más fracuentemente debido a bravezas (marejadas) generalmente invernales y secundariamente como resultado de crecidas fluviales. Paralelamente, observaciones de COOPER (2002) señalan que los estuarios de dominio fluvial y micromareales, en virtud de los sedimentos de canal más cohesionados, requieren mayores descargas para que se produzcan cambios morfológicos significativos. Complementariamente, análisis de RODRÍGUEZ et al. (2000), para un delta del Golfo de México, dominado por el oleaje, muestran que las influencias fluviales y del oleaje pueden darse alternada o conjuntamente. El asunto es que en ese delta se indica sectores de acumulación lagunar, por represamiento de parte de cordones litorales, con tendencia a interestratificación entre ambos tipos de facies, lo que puede hipotetizarse en el caso de Pichilemu (Fig. 19).

\section{Correlación (Fig. 1)}

Los elementos que contiene el sistema de la ensenada de Pichilemu se pueden hallar en
Chile en los casos citados por ARAYAVERGARA (1981 y 1983). Con respecto al apoyo de cronología absoluta, los resultados de MARTÍNEZ (1968), OTA \& PASKOFF (1993) y HERVÉ et al. (2003) son referencias de los extremos norte y sur de Chile Central, entre las que es posible interpolar hipótéticamente asunciones acerca de la edad de las formas estructuradas en embientes sedimentarios similares. Para poder sustentar mejor esta correlación es necesario buscar, en lo posible, restos datables o indicadores de paleo-ambientes en Te.

\section{Significado de la terraza Te}

De lo indicado en el punto anterior, la terraza estuarial Te, debido a que es ubicua en emplazamientos geomorfológicos similares a lo largo de la costa de Chile Central, conteniendo facies de sedimentos finos, es propuesta como referencia fundamental para casos como el de la ensenada de Pichilemu.

\section{CONCLUSIONES}

- La ensenada en zeta de Pichilemu debe haberse formado por lo menos a partir de momentos avanzados de la Transgresión Flandesa, si el nivel de 6 a $7 \mathrm{Ka}$ es cotejado con las curvas de nivel del mar citadas en la discusión.

- Como respuesta al mar de fondo significativo del SW, se puede asumir que la deriva litoral operó a profundidades cada vez menores, conformando barras, islasbarrera y flechas alineadas en zeta griega (Fig. 20, 1).

- La superficie Te debiera representar el nivel alcanzado por el relleno transgresivo en ambiente estuarial, como resultado de un contínuo represamiento generado por el sistema de barrera. Las primeras barreras pueden haberse formado como barreras transgresivas. El sistema fluvial debe haber drenado en canales anastomosados sobre Te, debido a sobrecarga de sedimentos (Fig. 20, 2), cuando su superficie pasó del estado subestuarial al subaéreo. Es deseable el hallazgo de 


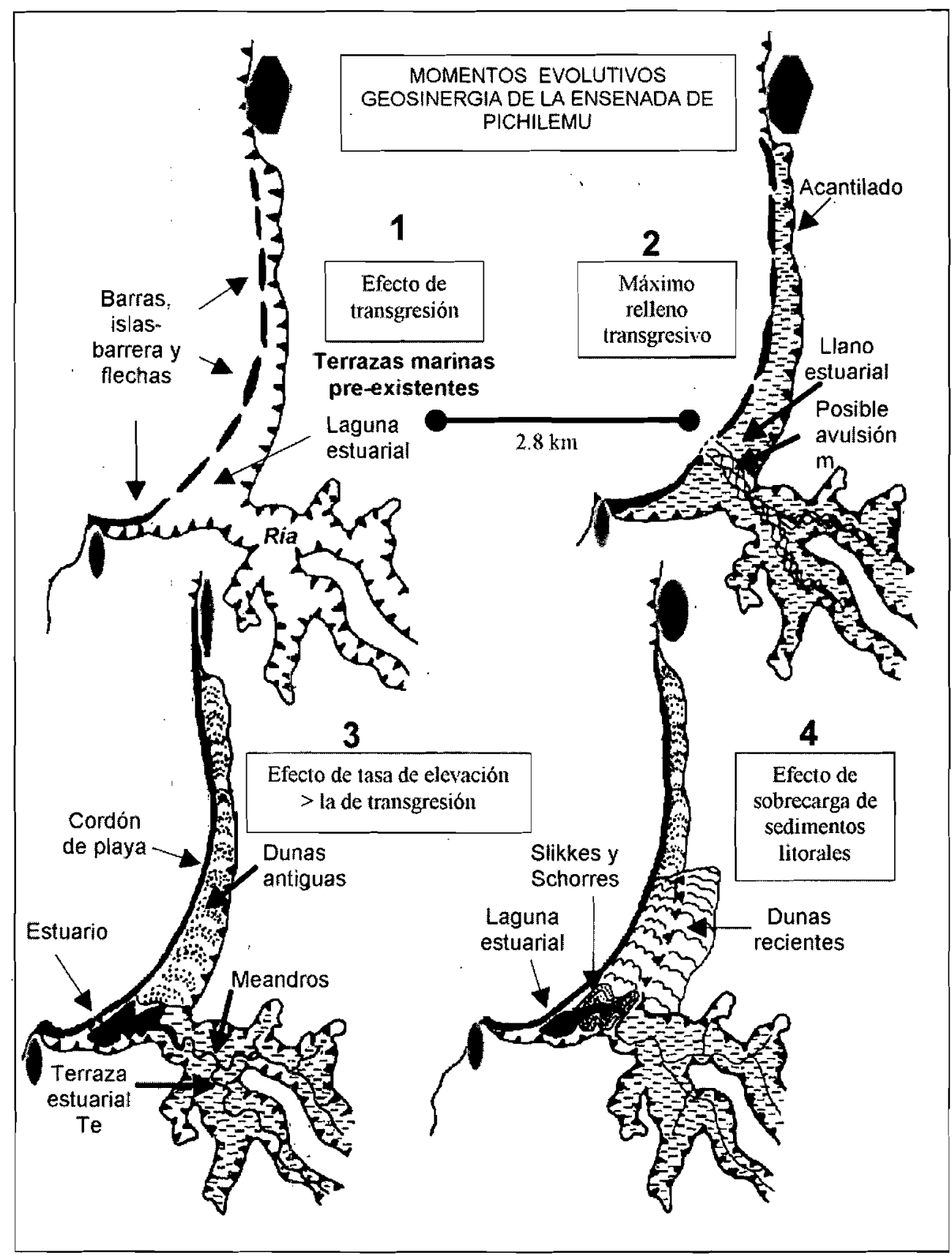

Fig. 20. Modelo evolutivo propuesto para el sistema.

Fig. 20. Evolutive model proposed for the system. 
elementos datables o que permitan reconstituir paleo-ambientes.

- Debido a la elevación de Te se debe haber producido su disección en canales meándricos, transformándose en terraza estuarial. La barrera en zeta debe haberse consolidado, facilitándose así la transferencia eólica de arena hacia el interior y formándose las dunas antíguas (Fig. 20, 3).

- Debido a la contínua deriva litoral, parece haberse producido inportante sobrecarga de sedimentos litorales, conformádose los mares de dunas transgresivas y aklé recientes. Las oscilaciones de la superficie de la laguna estuarial, debidas a episodios de inundación fluvial y de penetración de la onda de marea por ruptura de la barrera, se reflejan en los posibles slikkes y schorres y bancos deltaicos impersistentes (Fig. 20,4).

- Los elementos del sistema analizado permiten asociar el sistema estuarial y el de ensenada en zeta como una sola geosinergia, cuyos elementos se fueron generando sincrónicamente.

- Comparando los elementos del sistema de Pichilemu con los de otras ensenadas de la región ya citadas, se puede considerar que se trata de un prototipo regional de ensenada en zeta.

\section{AGRADECIMIENTOS}

El autor expresa su agradecimiento al Departamento de Investigación y Desarrollo de la Universidad de Chile por el auspicio de esta investigación y a la colega M. Victoria Soto Bäuerle, investigadora resposable del proyecto Análisis de las dimensiones físico-naturales de los ambientes litorales...borde costero...Pichilemu (título abreviado), por su constante colaboración. El manuscrito fue revisado acuciosamente por los Profs. Francisco Hervé y Oscar González-Ferrán de la Universidad de Chile, quienes aportaron importantes sugerencias.

\section{REFERENCIAS}

ANTHONY, E.J., L.M. OYÉDÉ \& J. LANG, 2002. Sedimentation in fluvially infilling, barrier bound estuary on a wavedominated, microtidal coast: the Ouémé River estuary, Benin, west Africa. Sedimentology, 49: 1095-1112.

ARAYA-VERGARA， J.F., 1967. Morfometría de la curvatura de las playas entre Punta de Talca y Punta Toro (Chile Central). Inform. geogr. Chile, 17: 5-30.

ARAYA-VERGARA, J.F., 1981. El concepto de delta en ría y su significado en la evolución litoral (ejemplo en Chile Central). Inform. geogr. Chile, 28: 71-102.

ARAYA-VERGARA, J.F., 1982. Beach orientation. In: Schwartz, M. (Ed.), Encyclopedia of beaches and coastal environments. Hutchinson Ross Publish. Co., Stroudsburg, Pa., pp. 149-150.

ARAYA-VERGARA, J.F., 1983. Influencias morfogenéticas de los desalineamientos y líneas de costa contrapuestas en el litoral de Chile Central. Inform. geogr. Chile, 30: 3-23.

ARAYA-VERGARA, 1986. Toward a classification of beach profiles. J. Coastal Res., 2(2): 159-165.

ARAYA-VERGARA, J.F., 1996. Sistema de interacción oleaje-playa frente a los ergs de Chanco y Arauco, Chile. Gayana Oceanol., 4(2): 159-167.

BLOOM, A.L., 1979. Atlas of sea level curves. Internat. Geol. Correl. Programme, Project 61: Sea level project. IUGSUNESCO, Ithaca, p. C40.

COOPER, J.A.G., 2001. Geomorphological variability among microtidal estuaries from the wave dominated South African coast. Geomorphology, 40: 99-122. 
COOPER, J.A.G., 2002. The role of extreme floods in estuary-coastal behaviour: contrasts between river- and tide-dominated coastal estuaries. Sedim. Geol., 150: 123-137.

CHAPMAN, D.M., 1982. Zeta-form bays. In: Schwartz, M. (Ed.), Encyclopedia of beaches and coastal environments. Hutchinson Ross Publish. Co., Stroudsburg, Pa., pp. 883-884.

DILLENBURG, S.R., P.S. ROY, P.J. COWELL \& L.J. TOMAZELLI, 2000. Influence of antecedent topography on coastal evolution as tested by the Shoreface Translation-Barrier Model (STM). J. Coastal Res., 16(1): 71-81.

DAVIES, J.L, 1977. Geographical variation in coastal development. Longman, London, 204 pp.

HERVÉ, F., A. ENCINAS, R. VILLAMARTÍNEZ, N. SVEN, K. FINGER \& D. PETERSON, 2003. Registro sedimentológico de la transgresión marina del Holoceno Medio en el área de Algarrobo (332' $\mathrm{S})$, Chile Central, etc. En: Actas $10^{\circ}$ Congreso Geológico Chileno, Univ. de Concepción, Dep. de Ciencias de la Tierra, Concepción, $\sin n^{\circ}$ de pág. (versión digital; $\mathrm{CD}$ ).

JOHNSON, D.W., 1919. Shore processes and shoreline development. J. Wiley, N. York, $584 \mathrm{pp}$.

MARTIN, L., K.SUGUIO \& FLEXOR, 1993. As fluctuações de nível do mar durante o Quaternário Superior e a evolução geológica de "deltas" brasileiros. Boletim IGUSP, Publ. Especial N ${ }^{\circ} 15$, São Paulo, 186 pp.

MARTíNEZ, R., 1968. Foraminíferos y evolución de la línea de costa holocénica en la zona de Concepción. En: Cecioni, G. (Ed.), El Terciario en Chile, Zona Central. Soc. Geol de Chile, Santiago, pp.211-258.
MARTÍNEZ, C., 2001. El efecto de ensenada en los procesos litorales de las ensenadas de Valparaíso, Algarrobo y Cartagena, Chile Central. Tesis para optar al grado de Magister en Geografía, Universidad de Chile, Fac. Arqu. y Urb., Escuela de Post-Grado. Santiago, $152 \mathrm{pp}$, Inédito.

MÖRNER, N.A., 1982. Sea level curves. In: Schwartz, M.L. (Ed.), Encyclopedia of beaches and coastal environment. Hutchinson Ross Publ. Co., Stroudsburg, Penn., pp. 729733.

ORME,A.R., 1988. Coastal dunes, changing sea level, and sediment budgets. J. Coastal Res., Sp. Issue, 3: 127-129.

OTA, Y. \& R. PASKOFF, 1993. Holocene deposits of the north-central Chile: radiocarbon ages and implications for coastal changes. R. Geol. de Chile, 20: 25-32.

OTVOS, E.G., 1982. Bruun rule. In: Schwartz, M.L. (Ed.).Encyclopedia of beaches and coastal environments. Hutchinson Ross Publ. Co., Stroudsburg, Pa., pp. 179-181.

PSUTY, N.P., 1986. Holocene sea level in New Jersey. Phys. Geogr., 7(2): 156-167.

PSUTY, N.P., 1988. Sediment budget and dune/beach interaction. J. Coastal Res., Sp. Issue, 3: 1-4.

RODRÍGUEZ, A.B., M.D. HAMLTON \& J.B. ANDERSON, 2000. Facies and evolution of the modern Brazos delta, Texas: wave versus flood influence. J. Sedim. Res., 70(2): 283-295.

SHORT, A.D. \& P.A. HESP, 1999. Beach and dune stratification. In: Short, A.D. (Ed.), Handbook of Beach and Shoreface Morphodynamics. John Wiley \& Sons Ltd., Chichester, pp. 280-292. 
SILVESTER, R., 1960. Stabilization of sedimentary coastlines. Nature, 188(47-49): 467-479.

STAPOR, Jr., F.W., 1982. Sea level changes, 1900 to present. In: Schwartz, M.L. (Ed.), Encyclopedia of beaches and coastal environments. Hutchinson Ross Publ. Co, Stroudsburg, Pa., p. 728-729.
VILLA-MARTÍNEZ, R. \& C. VILLAGRÁN, 1997. Historia de la vegetación de bosques pantanosos de la costa de Chile Central durante el Holoceno Medio y Tardío. R. Chil. Hist. Nat., 70: 391-401.

WRIGHT, L.D. \& A.D. SHORT, 1984. Morphodynamic variability of surf zones and beaches: A synthesis. Mar. Geol., 56: 93-118. YASSO, W.E., 1965. Plan geometry of headland-bay beaches. J. Geol., 73: 702-714.

\section{Imagen de Investigaciones GEOGRÁfICAS}

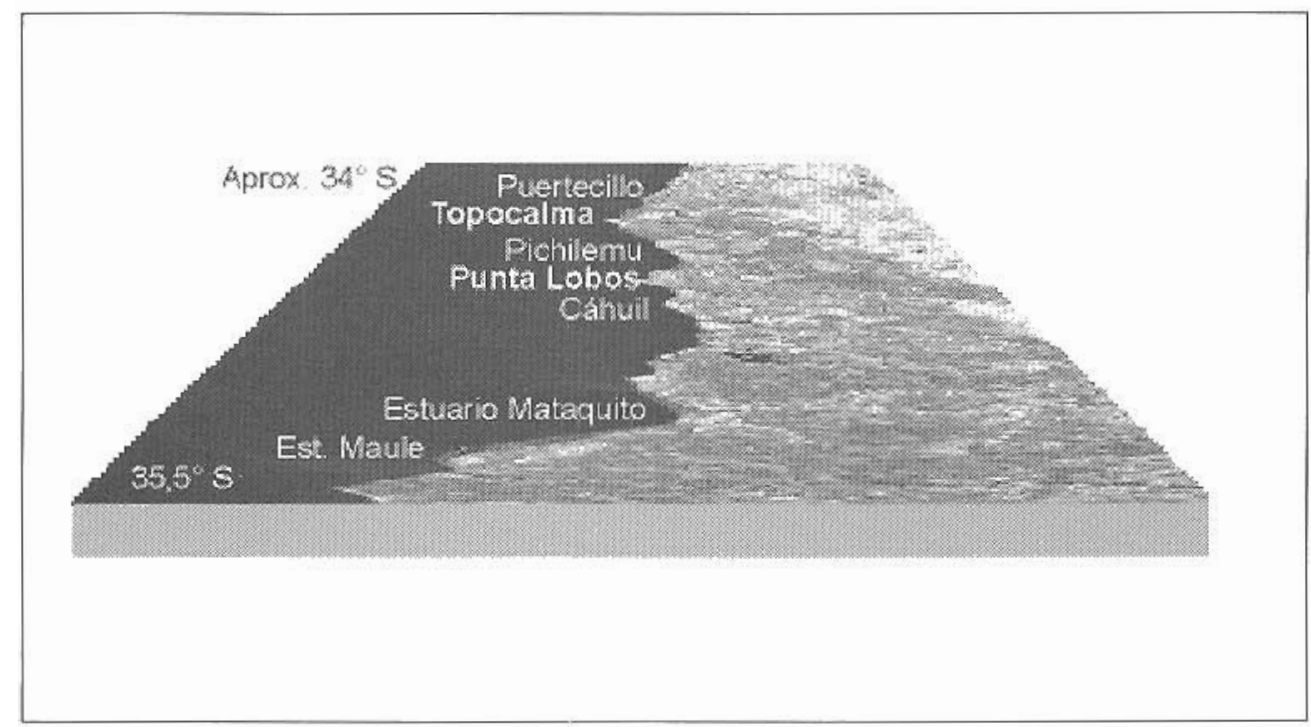

Bloque diagrama de imagen Landsat mostrando sectores de bahías en zeta en Chile Central y lugares de referencia para la terraza estuarial Te. 